\title{
๖The Physical Climate at Global Warming Thresholds as Seen in the U.K. Earth System Model $\mathscr{O}$
}

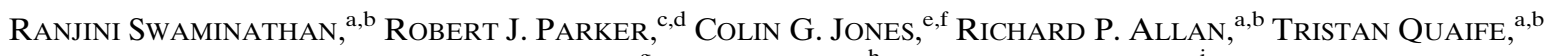 \\ DOUGLAS I. KELLEY, ${ }^{\mathrm{g}}$ LEE DE MORA, ${ }^{\mathrm{h}}$ AND JEREMY WALTON ${ }^{\mathrm{i}}$

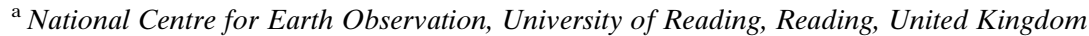 \\ ${ }^{\mathrm{b}}$ Department of Meteorology, University of Reading, Reading, United Kingdom \\ ${ }^{\mathrm{c}}$ National Centre for Earth Observation, University of Leicester, Leicester, United Kingdom \\ ${ }^{\mathrm{d}}$ Earth Observation Science, School of Physics and Astronomy, University of Leicester, Leicester, United Kingdom \\ ${ }^{\mathrm{e}}$ National Centre for Atmospheric Science, Leeds, United Kingdom \\ ${ }^{\mathrm{f}}$ School of Earth and Environment, University of Leeds, Leeds, United Kingdom \\ ${ }^{\mathrm{g}}$ U.K. Centre for Ecology and Hydrology, Wallingford, United Kingdom \\ ${ }^{\text {h }}$ Plymouth Marine Laboratory, Plymouth, United Kingdom \\ ${ }^{\mathrm{i}}$ Met Office Hadley Centre for Climate Science and Services, Exeter, United Kingdom
}

(Manuscript received 25 March 2021, in final form 12 September 2021)

\begin{abstract}
A key goal of the 2015 Paris Climate Agreement is to keep global mean temperature change at $2^{\circ} \mathrm{C}$ and if possible under $1.5^{\circ} \mathrm{C}$ by the end of the century. To investigate the likelihood of achieving this target, we calculate the year of exceedance of a given global warming threshold (GWT) temperature across 32 CMIP6 models for Shared Socioeconomic Pathway (SSP) and radiative forcing combinations included in the Tier 1 ScenarioMIP simulations. Threshold exceedance year calculations reveal that a majority of CMIP6 models project warming beyond $2^{\circ} \mathrm{C}$ by the end of the century under every scenario or pathway apart from the lowest emission scenarios considered, SSP1-1.9 and SSP1-2.6, which is largely a function of the ScenarioMIP experiment design. The U.K. Earth System Model (UKESM1) ScenarioMIP projections are analyzed in detail to assess the regional and seasonal variations in climate at different warming levels. The warming signal emerging by midcentury is identified as significant and distinct from internal climate variability in all scenarios considered and includes warming summers in the Mediterranean, drying in the Amazon, and heavier Indian monsoons. Arctic sea ice depletion results in prominent amplification of warming and tropical warming patterns emerge that are distinct from interannual variability. Climate changes projected for a $2^{\circ} \mathrm{C}$ warmer world are in almost all cases exacerbated with further global warming (e.g., to a $4^{\circ} \mathrm{C}$ warmer world).
\end{abstract}

SIGNIFICANCE STATEMENT: In this study, we look into changes occurring in climate due to global warming by analyzing data from the latest global climate models to see when the Earth will warm by $2^{\circ}$ or $4^{\circ} \mathrm{C}$, compared to preindustrial temperatures. We then use the UKESM1 climate model to identify regions on Earth where significant climate change is simulated in the future and discuss possible reasons for these changes. Simulations from this model also show that regions such as the Mediterranean, Amazon forests, and tropical countries are likely to see significant changes in climate impacting human lives. Future work to study the regional changes in greater detail will help us improve climate policies to protect society.

KEYWORDS: Anthropogenic effects/forcing; Climate change; Climate prediction; Temperature; Climate models; Regional effects

\section{Introduction}

Climate mitigation policy is often discussed in terms of limiting globally averaged surface warming to a predefined target, or a global warming threshold (GWT). For instance, the Paris Climate Agreement, signed at the 21st United Nations Climate Change Conference in 2015 (Rhodes 2016) outlined

๑ Denotes content that is immediately available upon publication as open access.

Supplemental information related to this paper is available at the Journals Online website: https://doi.org/10.1175/JCLI-D-210234.s1.

Corresponding author: Ranjini Swaminathan, r.swaminathan@ reading.ac.uk two key goals: 1) to keep the increase in global mean surface temperatures, relative to preindustrial (i.e., 1850-1900) values, to below $2^{\circ} \mathrm{C}$ and 2) to simultaneously pursue pathways that would limit warming to $1.5^{\circ} \mathrm{C}$. While these targets are phrased in terms of global mean surface temperature change (which is useful for assessing how $\mathrm{CO}_{2}$ emissions ultimately lead to planetary warming), policymakers will have to consider the impacts of climate change at the regional and national levels they represent. Therefore, it is essential to quantify and fully understand the regional characteristics of climate change at different GWTs.

While changes in regional climate, including climate extremes and their impacts, are strongly linked to the degree of global mean warming (Hoegh-Guldberg et al. 2018; Iturbide et al. 2021), local feedbacks can amplify (or dampen) the global mean signal, resulting in regional differences in magnitude as well as time of onset of an emergent change signal (Stuecker et al. 2018; Harrington et al. 2018, 2016). Furthermore, there is 
increasing concern about the risk of rapid change occurring in different components (and regions) of the Earth system as global mean temperatures increase beyond those experienced within recorded history (Lenton et al. 2019; Lee et al. 2021). With such regional tipping points in mind, it is critical to fully understand how a given global mean warming translates into regionally and seasonally specific climate change.

Previous studies have investigated when certain GWTs, such as $2^{\circ} \mathrm{C}$, are exceeded in ensembles of climate model projections. Joshi et al. (2011) focus on threshold exceedance timing in CMIP3 data for the purpose of adaptation and highlight the regional distribution of exceedance years as being relevant for policy making. Hauser et al. (2019) calculate threshold exceedance in a similar way to our study but do not perform any regional analysis of change. Other studies have focused on the impact of reaching $1.5^{\circ} \mathrm{C}$ warming or the advantages of restricting warming to $1.5^{\circ} \mathrm{C}$ relative to $2^{\circ} \mathrm{C}$-for example, the IPCC Special Report on $1.5^{\circ} \mathrm{C}$ warming (Hoegh-Guldberg et al. 2018) is a detailed study of the impacts and mitigation measures needed to keep warming levels at $1.5^{\circ} \mathrm{C}$ and $\mathrm{Jacob}$ et al. (2018) focus on the varied societal impacts of warming to $1.5^{\circ} \mathrm{C}$ in Europe. Schleussner et al. (2016) look at several indicators such as sea level rise, extreme weather, and water availability to illustrate the difference in $1.5^{\circ}$ versus $2^{\circ} \mathrm{C}$ warming. Other work discussing the comparative impacts of thresholds includes King et al. (2017), who study the reduction of extreme heat events in Australia by keeping to the lower threshold, Huang et al. (2017) on the difference in warming of drylands over humid lands, and Nikulin et al. (2018) on the use of CORDEX regional model ensembles to study changes in surface temperature and precipitation over Africa under different future scenarios.

In this study we revisit the question of when different GWTs will be exceeded. We do this using the latest ScenarioMIP projections (O'Neill et al. 2016) from phase 6 of the Coupled Model Intercomparison Project (CMIP6), analyzing five future Shared Socioeconomic Pathway (SSP)-based scenarios (Riahi et al. 2017), and ask when key GWTs will be exceeded and how these dates vary across CMIP6 models and scenarios. Each ScenarioMIP SSP represents an assumed future socioeconomic development pathway (O'Neill et al. 2014; Riahi et al. 2017) that ranges from a sustainable future (SSP1) through to a fossil fuel intense future (SSP5). Each SSP is associated with a time series of future greenhouse gas and aerosol emissions and land use changes that result in a global-mean, top of atmosphere (TOA)-positive net radiative forcing through to 2100 and beyond. The radiative forcing and associated atmospheric greenhouse gas concentrations are referred to as the representative concentration pathways (RCPs), which by year 2100 result in a global mean TOA radiation perturbation that ranges from $1.9 \mathrm{~W} \mathrm{~m}^{-2}$ (SSP1-1.9) to $8.5 \mathrm{~W} \mathrm{~m}^{-2}$ (SSP58.5). More details on the RCPs can be found in Moss et al. (2010) and Taylor et al. (2009). We use CMIP6 projections that sample the four Tier 1 ScenarioMIP pathways, namely SSP1-2.6, SSP2-4.5, SSP3-7.0 and SSP5-8.5, and additionally SSP1-1.9, which have global mean radiative forcings at 2100 of $2.6,4.5,7.0,8.5$, and $1.9 \mathrm{~W} \mathrm{~m}^{-2}$, respectively. Tebaldi et al. (2021) perform a similar GWT exceedance years for different
SSPs in CMIP6 models but limit their analysis to simple descriptive statistics for two climate variables.

We explore in detail three primary questions of relevance to the 2015 Paris Climate Agreement:

1) For a range of future scenarios and CMIP6 models, when in the future are specific global warming thresholds $\left(1.5^{\circ}, 2^{\circ}\right.$, $3^{\circ}, 4^{\circ}$, and $5^{\circ} \mathrm{C}$ ) exceeded and what is the spread of these exceedance years across the scenarios and models?

2) In the case of the U.K. Earth System Model (UKESM1; Sellar et al. 2019), how does a given global mean warming (e.g., $2^{\circ}$ or $4^{\circ} \mathrm{C}$ ) translate into seasonal-mean, regionally discrete climate change? In particular, are there regions and seasons where regional climate change is significantly larger (or smaller) than the global mean signal and how sensitive are these changes to the scenario or pathway taken to get to the threshold?

3) With reference to $2^{\circ} \mathrm{C}$ global mean warming, what are the relative differences in the seasonal-mean regional changes at warmer $\left(4^{\circ} \mathrm{C}\right)$ or cooler $\left(1.5^{\circ} \mathrm{C}\right)$ global mean levels? Do regional changes scale with the level of global mean warming or are there nonlinear changes at regional levels?

We use a multimodel CMIP6 ensemble to position UKESM1 among the latest Earth system models in the framework of global warming threshold exceedances and then focus the rest of our analysis on UKESM1. We believe this enables us to get a clear picture of the scale of changes with warming and allows us to more readily explore some of the underlying causes for these changes. We acknowledge that this is a regional study based on a single model and thus has its limitations but the methodology developed and insights gained through this work will enable a more robust multimodel analysis subsequently. We also focus on changes over land regions in this study because we wish to study warming related physical changes in climate that are most relevant for human impacts.

Section 2 details the data and methods we use for our analysis, and section 3 describes the results from our analysis first by looking at threshold exceedance year occurrences across scenarios and CMIP6 models. We then study warming pattern dependencies on scenarios in UKESM1 before looking at changes in physical climate variables at warming thresholds. This includes looking at the latitudinal variations in temperature and water cycle variables across warming thresholds, the ratio of regional change in warming to the global mean (which regions warm more or less than the global mean), changes going from lower to higher threshold values, differences in land and ocean warming, and the significance of the warming signal itself (how does regional warming compare to model internal variability). In section 4 , we analyze some of the possible underpinning physical causes for the regional patterns seen in the UKESM1 projections. We conclude with a brief summary including a discussion of the limitations in our study and outline future research directions in section 5 .

\section{Data and methods}

Data from 32 Earth system models submitted to CMIP6 (Eyring et al. 2016) are used in our analysis of GWT exceedances. The first ensemble member is used from each model, and in the case of UKESM1 (Sellar et al. 2019) 13 different ensemble 
members are considered. A list of the models and ensemble members used is given in Table A1 in appendix A. For our analysis, we use data from three separate experiments: the preindustrial control (pi-control), historical, and ScenarioMIP simulations for Tier 1 Scenarios SSP1-2.6, SSP2-4.5, SSP3-7.0, and SSP5-8.5 as well as SSP1-1.9. The ScenarioMIP simulations were chosen to cover a wide range of possible futures, from sustainably focused growth and equality (SSP1) to the "middle of the road" world with trends following historical patterns (SSP2) and the extreme case of intense economic growth and fossil fuel energy use (SSP5). More details on the different ScenarioMIP experiments can be found in O'Neill et al. (2016). Climate variables analyzed [with reference to their netCDF Climate Model Output Rewriter (CMOR) abbreviation provided in parentheses] include surface temperature at $1.5 \mathrm{~m}$ (tas), which we refer to as surface temperature in this paper, precipitation $(\mathrm{pr})$, soil moisture $(\mathrm{sm})$, precipitation minus evaporation $(P-E)$ and sea ice percentage (siconca). Other variables used to support our analysis were cloud variables such as net cloud radiative effect (ncre), liquid water path (lwp), cloud cover (clt), vegetation variables such as tree fraction (treeFrac), and land ice variable, snow cover (snc). The figures in this paper were produced with the Earth System Model Evaluation Tool (ESMValTool) (Righi et al. 2020; Andela et al. 2021a,b), a community-driven, open source tool for climate model evaluation. ESMValTool was also used to obtain derived variables (such as ncre) from native CMIP6 variables.

\section{a. Calculating global warming thresholds}

We define a global warming threshold (GWT) as a specific value of global mean surface air temperature (GSAT), calculated as an anomaly with respect to the GSAT average for 1850-1900 (a proxy for preindustrial conditions). To limit the influence of short-term variability, we apply a 21-yr centered running mean to the ScenarioMIP GSAT values from each model's ensemble member. Our algorithm for calculating a GWT exceedance year is presented in Algorithm 1 (see appendix B). Where there is more than one ensemble member for a model or in the case of multiple models, the mean of the member anomalies is first calculated before finding the exceedance year.

Figure 1 illustrates our algorithm for a specific GWT and ensemble member. We experimented with 5-yr running means centered around a given year and also calculated means for 5- or 21-yr time periods preceding each year. We discuss results from these experiments in section $3 \mathrm{a}$.

\section{b. Zonal and spatial mean calculations}

For all our spatial and zonal variable analysis, we calculate the 20-yr climatological means around threshold exceedance years and subtract them from the 1850-1900 mean values. In the case of sea ice plots, anomaly values are calculated for area averaged means.

\section{Results}

\section{a. Timing of global warming threshold exceedances}

Figure 2 shows the spread of exceedance years for the selection of CMIP6 models under different future scenarios and for different GWTs. As described in section 2a, we compute a

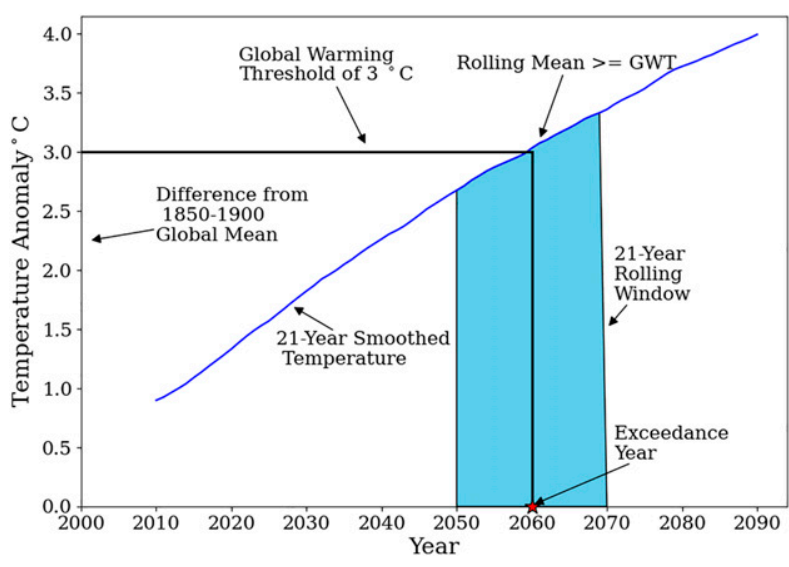

FIG. 1. Global warming threshold (GWT) exceedance year computation: For each historical member and subsequent scenario pathway, a 21-yr centered running-mean GSAT anomaly is calculated with respect to the 1850-1900 mean GSAT. The first year this anomaly exceeds a given threshold temperature value for a given ensemble member (or ensemble mean) is taken as the year of exceedance for that ensemble member (or ensemble mean). An illustration of this calculation of the exceedance year for a GWT of $3^{\circ} \mathrm{C}$ is shown in the figure.

running average over a 21-yr period of surface air temperature anomalies and calculate the exceedance year as the point when the center in the 21-yr period exceeds a given threshold temperature. Since we only use ScenarioMIP projections running up to the year 2100 , this limits our ability to calculate exceedance years beyond 2090 when using the centered 21-yr moving-average approach. Hence, in Fig. 2 we use dashed lines extending beyond the solid colored bars wherever we have insufficient evidence to determine if a given model simulation exceeds a certain threshold. We take care not to assume the exceedance year as 2100 for such models to avoid artificially early estimates of multimodel exceedance year statistics as explained in Hawkins et al. (2014). We also report the multimodel median year (instead of the mean) of exceedance only where a majority of models (greater than half) exceed a given threshold for any scenario. This is to limit the bias on the reported median exceedance year when a very small number of models actually exceed a threshold by 2100 because in a multimodel mean statistic models with higher climate sensitivity would dictate warming patterns, particularly at higher thresholds. The exceedance dates should therefore be viewed as an early estimate when there are models that fail to exceed a given threshold by 2090. ScenarioMIP Tier 2 long-term projections are available beyond 2100 , but only for a limited number of experiments and so are not used within the scope of this paper.

Global surface air temperature changes are calculated relative to preindustrial levels where "preindustrial" refers to the period before any anthropogenic interference (due to industrialization and fossil fuel combustion) was introduced into the climate system. Hawkins et al. (2017) suggest the 1720-1800 period as most suitable to be considered as preindustrial but recognized the 1850-1900 period as a reasonable surrogate with no statistically significant difference. Some studies (Schurer et al. 2017; Tebaldi et al. 2021) calculate warming with respect 
Global Warming Threshold Exceedance in CMIP6 Models

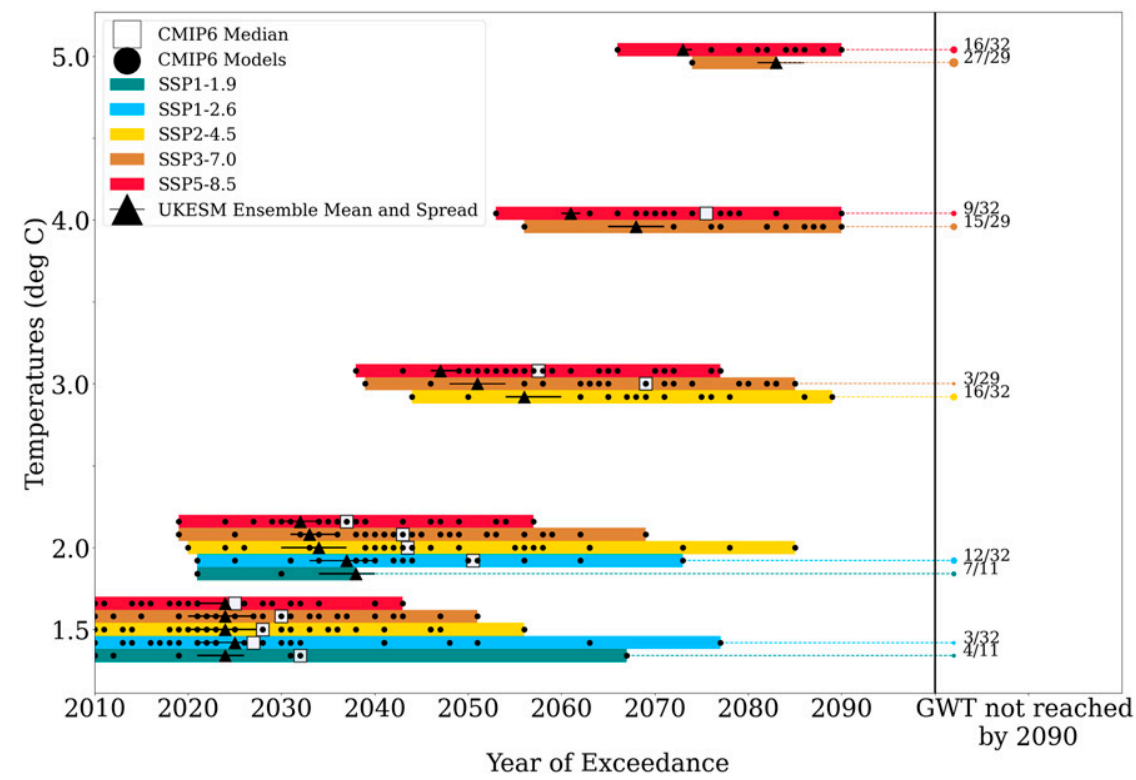

FIG. 2. Global warming threshold (GWT) exceedance years for 32 CMIP6 models. The colored bars represent the temporal spread of threshold exceedance years for all models that exceed a GWT value under different SSPs when calculated with respect to 1850-1900 mean temperatures. Threshold exceedance years for individual CMIP6 models are denoted as circles and the multimodel median is shown as a square. The UKESM1 model's ensemble mean is further distinguished as a triangle with the ensemble member spread for UKESM1 shown by the black line through the mean. The colored dashed lines indicate when a subset of models do not exceed a certain threshold with the fraction at the end indicating the proportion of models that do not. For the higher GWT values, this becomes a significant number and for certain SSPs no models exceed the higher GWT thresholds.

to a present day time period and add an offset to better estimate present-day warming since preindustrial conditions. Other studies (King et al. 2017) have compared baseline periods from observations with historical simulations and found no significant differences. Assessing a range of observational and modeling evidence as part of the IPCC AR6 report (under review at the time this paper was written), Chen et al. (2021) estimate that the temperature change from 1750 to the 1850-1900 period is $-0.1^{\circ}$ to $0.3^{\circ} \mathrm{C}$. We acknowledge the uncertainty involved in determining the most suitable time period that represents preindustrial temperatures but for the purpose of this study, use the 1850-1900 baseline in alignment with the IPCC AR6 report. Our goal is to study the distribution of threshold exceedance years across CMIP6 models under different scenarios but also to understand how UKESM1 is positioned relative to other CMIP6 models in this context. This positioning will remain independent of the offset or preindustrial mean chosen. Furthermore, the magnitude of the difference in global mean temperature between the 1100 -yr run of the picontrol experiment and the 1850-1900 means in UKESM1 is small enough $\left(0.05^{\circ} \mathrm{C}\right.$ for the DJF season and $-0.02^{\circ} \mathrm{C}$ for the JJA season) to negate the need for an additional offset to account for any difference between preindustrial and 1850-1900 mean conditions. In what follows we therefore use the 1850-1900 mean period as a surrogate for preindustrial conditions and calculate global warming exceedance years relative to this period.
In Fig. 2, we see that 4 out of 11 models under SSP1-1.9 do not exceed $1.5^{\circ} \mathrm{C}$ by the end of the century, with three additional models not exceeding $2^{\circ} \mathrm{C}$ and none at all exceeding $3^{\circ} \mathrm{C}$. Fewer than $10 \%$ of models do not exceed $1.5^{\circ} \mathrm{C}$ under SSP1-2.6 and just over a third do not exceed $2^{\circ} \mathrm{C}$. All models exceed $2^{\circ} \mathrm{C}$ under the other scenarios. In the case of higher thresholds, we see that about half the models do not exceed $4^{\circ} \mathrm{C}$ by the end of the century under SSP3-7.0 although over $70 \%$ of the models, including UKESM1, exceed that threshold under SSP5-8.5. As expected the spread of models around a median exceedance year increases for more weakly forced SSPs as well as for higher GWT thresholds and an increasing number of models do not exceed the higher thresholds. For instance, for the middle range scenario SSP2-4.5, the span of years for models to exceed $1.5^{\circ} \mathrm{C}$ is 45 years but for $2^{\circ} \mathrm{C}$ it is almost 70 years, indicating that models with lower climate sensitivity are likely taking longer to exceed the thresholds and ultimately not exceeding them.

Except under SSP1-1.9, the UKESM1 ensemble means exceed $1.5^{\circ} \mathrm{C}$ within six years of the multimodel median. At higher warming thresholds, this difference increases and is largest under the more weakly forced scenarios for each threshold (13 years under SSP1-2.6 for $2^{\circ} \mathrm{C}, 18$ years under SSP3-7.0 for $3^{\circ} \mathrm{C}$, and 14 years under SSP5-8.5 for $4^{\circ} \mathrm{C}$ warming). This indicates that UKESM1 ensemble members warm faster than many of the other models, consistent with its higher transient climate response (Meehl et al. 2020; Andrews 

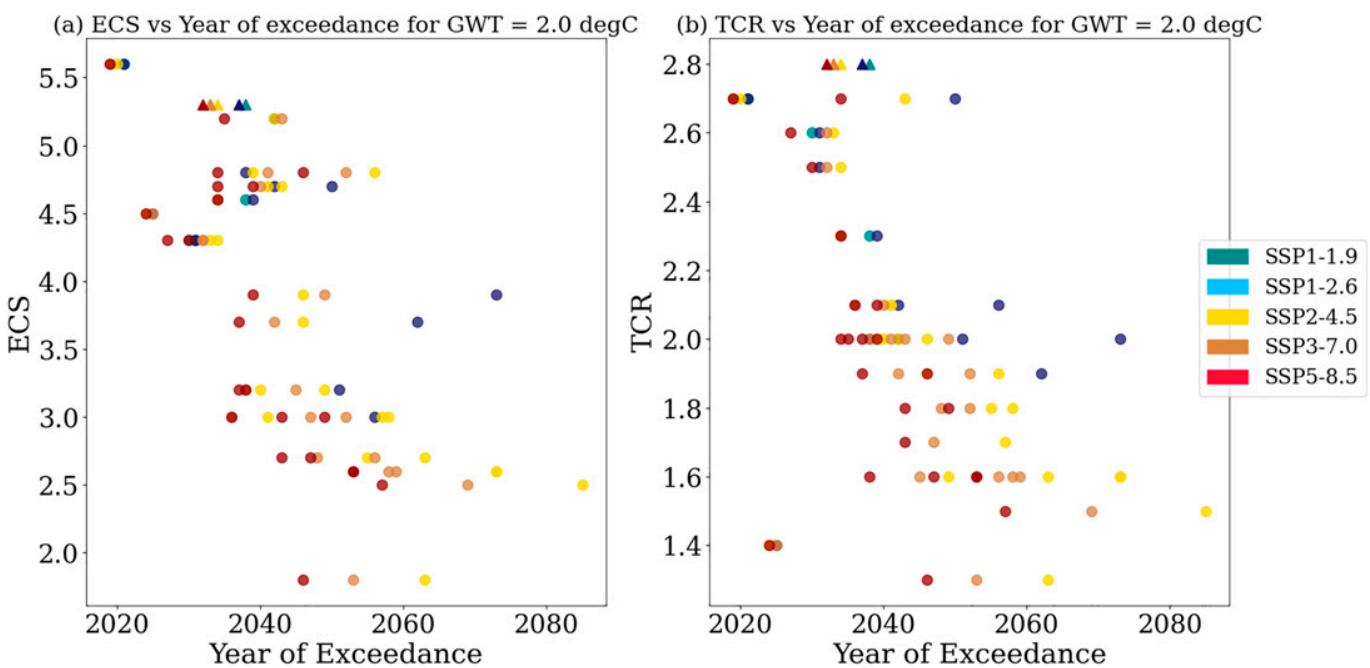

FIG. 3. Scatterplot showing the relationship between the years of exceedance and climate sensitivity metrics at $2^{\circ} \mathrm{C}$ warming for 24 CMIP6 models and different scenarios. (a) The year of exceedance against equilibrium climate sensitivity. (b) The year of exceedance against transient climate response. UKESM1 values are shown as triangles.

et al. 2019). The range of warming threshold exceedance years across scenarios is generally smaller for UKESM1 than the model ensemble median range-for $1.5^{\circ} \mathrm{C}$, the range is two years, for $2^{\circ} \mathrm{C}$ it is 6 years, and it further increases going to 10 years for $5^{\circ} \mathrm{C}$ warming. This may reflect the relatively high climate sensitivity of UKESM1, which also plays a role in reducing climate change differences across scenarios at each warming threshold as described in Herger et al. (2015).

To assess the influence of a model's climate sensitivity on its warming exceedance year, we look at two metrics. The first is the equilibrium climate sensitivity (ECS), a value of global warming at equilibrium for a doubling of $\mathrm{CO}_{2}$, and the second is the transient climate response (TCR), the surface temperature warming around the time of $\mathrm{CO}_{2}$ doubling in a $1 \% \mathrm{yr}^{-1}$ $\mathrm{CO}_{2}$ increase simulation. Figure 3 is a scatterplot of the relationship between ECS and TCR with threshold exceedance years for global warming of $2^{\circ} \mathrm{C}$ in the CMIP6 models. We use ECS and TCR values reported for the 24 CMIP6 models in common with Meehl et al. (2020) for our analysis. While there is clearly a relationship between early exceedance years for a given threshold and a model's ECS or TCR, the relationship does exhibit some scatter. We note that UKESM1 has a relatively high ECS and TCR value and this will be the leading cause of it having relatively early exceedance years per warming threshold. The spread in the relationship may be a result of internal variability and that we only sample one realization per model (Hawkins and Sutton 2009). A more likely explanation is related to the magnitude of aerosol forcing in a given model. Both the abrupt $4 \times \mathrm{CO}_{2}$ and $1 \%$ transient $\mathrm{CO}_{2}$ runs, from which ECS and TCR are calculated, use fixed preindustrial aerosol loading, whereas the SSP simulations include time varying aerosols through both the historical and future periods. In the SSP runs a strong (negative) aerosol forcing may therefore partially balance a model's high ECS or TCR, delaying warming (and exceedance year) compared to an equivalent ECS/TCR model with a weaker aerosol forcing. We further see that exceedance years for $2^{\circ} \mathrm{C}$ are ordered by the strength of the applied forcing, with SSP5-8.5 being the earliest, followed by SSP3-7.0 and so on. In a multimodel context, the removal of models with higher climate sensitivities may have an effect on statistics that inform us about the likelihood of reaching specific warming thresholds by the end of the century. While climate sensitivity clearly plays a role, we focus on the actual changes in UKESM1 at individual thresholds, which provides a degree of independence from the time taken to reach the threshold. We nevertheless acknowledge that UKESM1 has a relatively early exceedance year for each warming threshold when compared to the spread of CMIP6 models and that this is primarily related to the high ECS and TCR of this model.

Overall, the CMIP6 projections are consistent with the expectation that sustainable growth scenarios with mitigation, such as SSP1-2.6, limit the amount of warming over the next century, as opposed to the fossil fuel intensive energy usage scenarios as in the case of SSP5-8.5 where half the models available exceed $5^{\circ} \mathrm{C}$ warming before the end of the century. Using a shorter (5-yr) time window as in Smith et al. (2018) did not noticeably alter the GWT exceedance year but it is noted that using the last year of an averaging period to mark the exceedance time, mimicking real-time climate monitoring, will shift the exceedance forward in time by half of the averaging period length.

We next look at regional and seasonal changes in patterns of key climate variables at different global warming levels. For this analysis we concentrate on UKESM1 but acknowledge that an important extension will be to assess the robustness of our findings across the CMIP6 multimodel ensemble. We note that SSP3-7.0 is a scenario with substantial land use change and high near-term climate forcer emissions but we use a large ensemble of SSP3-7.0 (13 members) as a representative scenario and forcing combination for most of our analysis since this scenario 1) is considered particularly relevant for regional impacts assessments as well as vulnerability studies (O'Neill et al. 2016), 2) reaches all global warming thresholds up to $5^{\circ} \mathrm{C}$ 

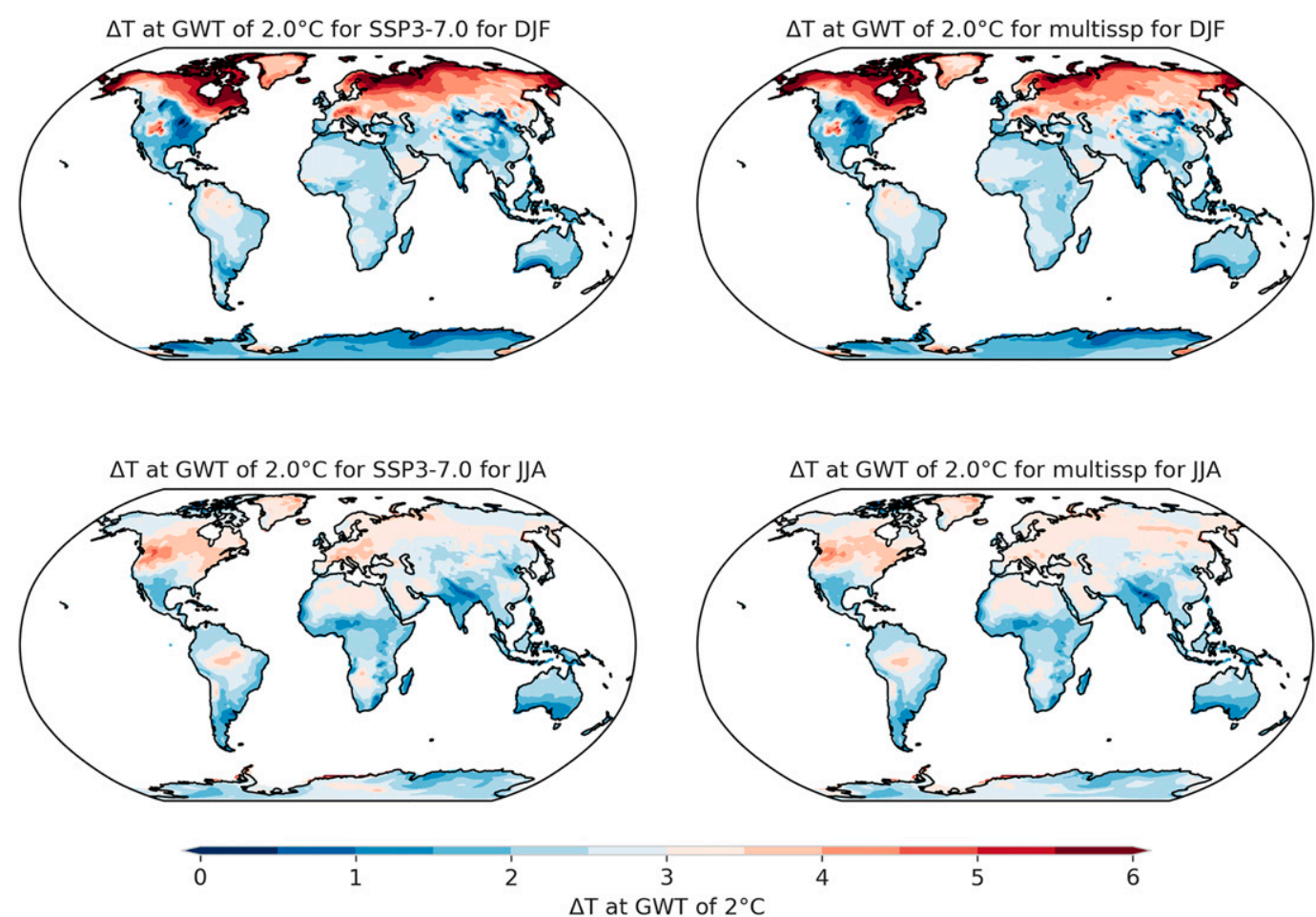

FIG. 4. Spatial changes in warming at $2^{\circ} \mathrm{C}$ for SSP 3-7.0 and multiscenario means: (top) DJF warming patterns and (bottom) JJA changes.

by the end of the century in the UKESM1 simulations, and 3) combines relatively high societal vulnerability (SSP3) with relatively high forcing. We determined that using GWT exceedance as our anchor point for analyzing future climate change to a large degree decouples this analysis from dependence on a given scenario pathway. In the next section we assess whether using only the SSP3-7.0 scenario or the full multiscenario ensemble influences our main findings.

\section{b. Sensitivity to different scenario pathways}

We go on to examine how different scenario pathways influenced regional patterns of surface temperature and precipitation change at different global warming thresholds. In doing so we wish to assess whether for a given global warming threshold (e.g., $2^{\circ}$ or $4^{\circ} \mathrm{C}$ ) the scenario pathway followed to reach that threshold has a major impact on the resulting distribution or magnitude of changes. In general for UKESM1, we found this was not the case and that the particular scenario followed to reach the threshold only had a minimal impact on the resulting regional changes. Figure 4 plots changes in DJF and JJA mean surface air temperature simulated by UKESM1 at $2^{\circ} \mathrm{C}$ global warming relative to the $1850-1900$ mean. Changes are plotted based on using 1) only the SSP3-7.0 ensemble and 2) all scenarios that exceed the given threshold. Figure 5 plots the same seasonal temperature change in going from a global warming value of $2^{\circ}$ to $4^{\circ} \mathrm{C}$ for the same SSP3-7.0 and multiscenario ensembles. At $2^{\circ} \mathrm{C}$ global warming nearly all the regional patterns of warming seen in the multiscenario ensemble are also captured in the SSP3-7.0 ensemble.
This includes the large amplification of warming in the far Northern Hemisphere in DJF and the relative minima in warming across the central United States, apart from over the Rockies where warming may be tied to a snow-albedo feedback response. The Amazon shows an amplification of warming in DJF in both ensembles and the Indian subcontinent relatively reduced warming, presumably linked to intensified monsoon rainfall and surface evaporation. The majority of the regional warming patterns are also largely consistent across the two ensembles in JJA and for both seasons when global mean warming increases from $2^{\circ}$ to $4^{\circ} \mathrm{C}$.

We further quantified these changes (here we included ocean as well to ensure better representation of processes) by scaling the variability or standard deviation across individual scenario ensemble members with the global mean at each model grid point (Fig. 6). We find that the magnitude of the change is very small (under $0.2^{\circ} \mathrm{C}$ ) globally and up to $0.6^{\circ} \mathrm{C}$ in parts of the Arctic for DJF likely due to small geographical differences in sea ice changes across the multiscenario ensemble. We also analyzed changes in water cycle variables such as precipitation and soil moisture and found that changes at $2^{\circ} \mathrm{C}$ global warming and on going from $2^{\circ}$ to $4^{\circ} \mathrm{C}$ are very similar for a multiscenario ensemble mean and an SSP3-7.0 ensemble mean. These figures are presented in a separate document (see the online supplemental material) for the interested reader.

\section{c. Changes in surface temperature}

Figure 7 shows the change in global (land and ocean) zonal mean surface temperature (compared to the 1850-1900 period) 

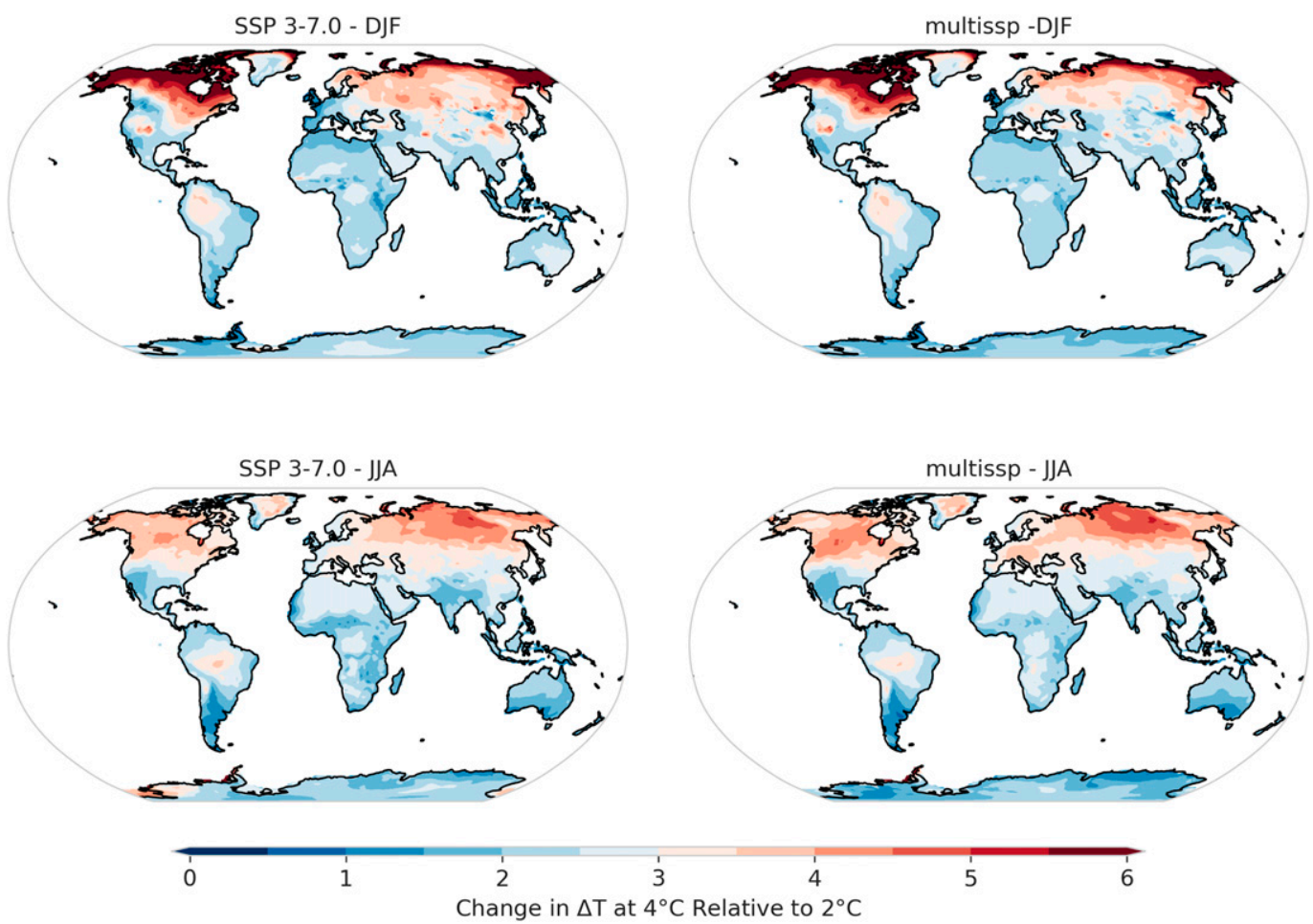

FIG. 5. Spatial changes in warming going from $2^{\circ}$ to $4^{\circ} \mathrm{C}$ for SSP3-7.0 and multiscenario means: (top) DJF warming patterns and (bottom) JJA changes.

at different warming thresholds. Outside the polar regions, the zonal mean temperature change is very close to the GWT. Arctic warming is about 4 times greater than the global mean at a GWT of $5^{\circ} \mathrm{C}$ (Fig. $7 \mathrm{~d}$ ) and appears to increase from an amplification of $\sim 2.5$ at GWT of $1.5^{\circ} \mathrm{C}$ and 3 at $\mathrm{GWT}=2^{\circ} \mathrm{C}$. Arctic winter (DJF) warming increases from a factor of 4 at $\mathrm{GWT}=2^{\circ} \mathrm{C}$ to greater than 6 at $\mathrm{GWT}=4^{\circ} \mathrm{C}$ and above (Fig. 7e). Arctic warming in the summer season (JJA) is only marginally greater than the global mean warming, with a decrease toward the pole. Antarctic amplification in the Southern Hemisphere winter is spatially linked to the location of sea ice in the historical simulation. The Antarctic amplification is smaller in magnitude than in the Arctic, between 2 and 3 times the GWT at $65^{\circ} \mathrm{S}$ during the winter season (JJA), and is less than the global mean warming in the summer season (Fig. 7f). The zonal plots also show that the relative warming in the Antarctic sea ice is larger at lower GWTs but the absolute changes in temperature are greater at higher GWTs.

Figure 8 plots the spatial distribution of surface temperature change normalized by the value of the global warming threshold for the DJF and JJA seasons. GWTs of $1.5^{\circ}, 2^{\circ}$, and $4^{\circ} \mathrm{C}$ are plotted. We only plot changes over UKESM1 land
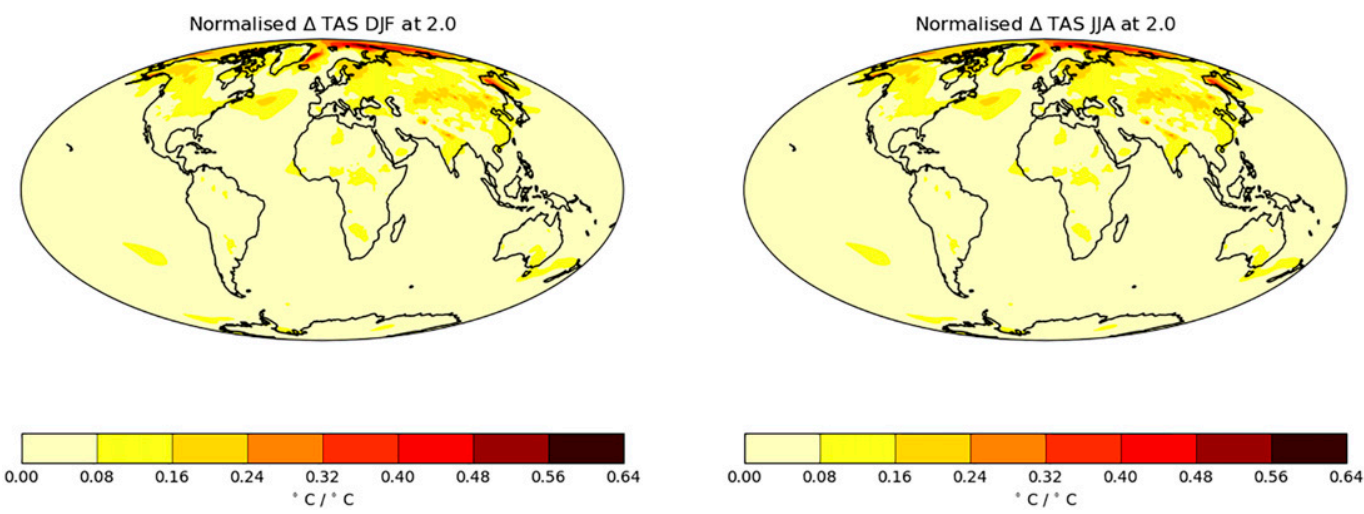

FIG. 6. Standard deviations of surface temperature changes across Tier1 UKESM SSPs at $2^{\circ} \mathrm{C}$ warming scaled by the global mean temperature. 


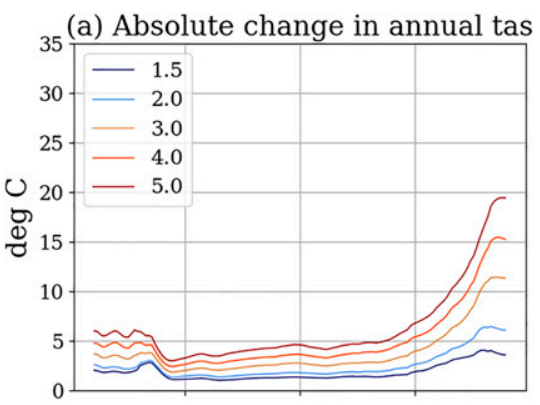

(d) Ratio of change in annual tas

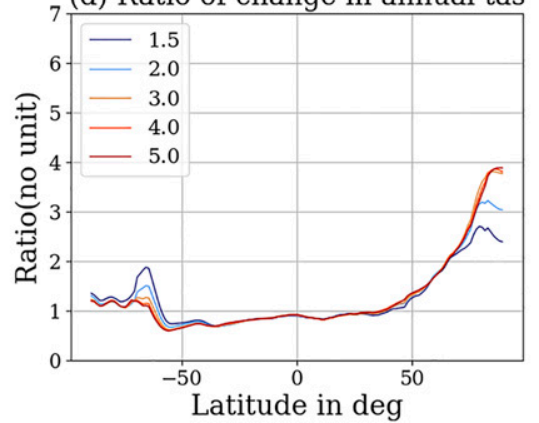

(b) Absolute change in djf tas

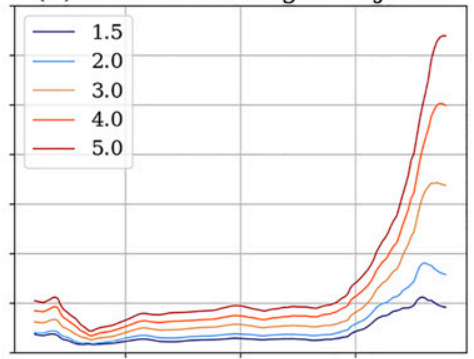

(e) Ratio of change in djf tas

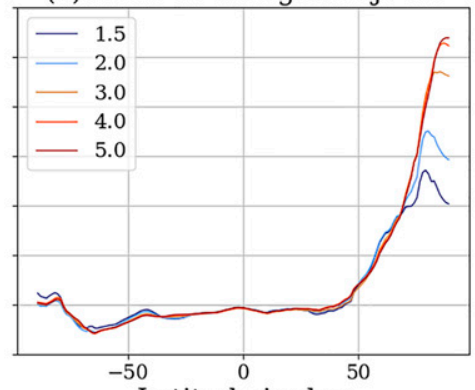

Latitude in deg (c) Absolute change in jja tas

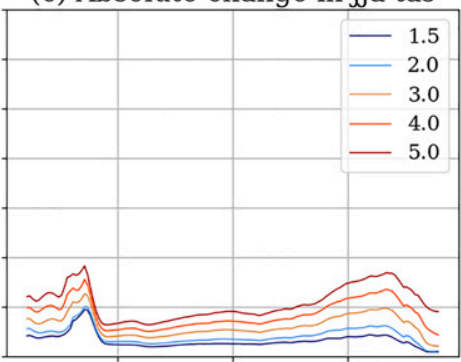

(f) Ratio of change in jja tas

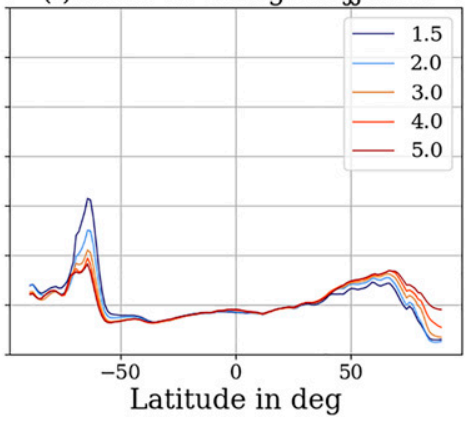

FIG. 7. Zonal mean surface temperature for annual and the DJF and JJA seasons for different global warming thresholds. (top) The absolute difference between 21-yr mean temperatures centered around global warming threshold exceedance years and the 1850-1900 mean. (bottom) The ratio of this mean difference in temperature to the global warming threshold. All plots are drawn for UKESM1 SSP37.0 ensemble members.

points and observe that the spatial patterns of normalized surface temperature show the largest changes in the Northern Hemisphere high latitudes. In the DJF season, it is largely the northern high latitudes where warming is twice the global mean whereas in the JJA season the northern United States and southern Canada, western Europe and the Mediterranean, parts of the Arabian peninsula and the Middle East, the Amazon, southwest Africa, and northern Europe/Russia show warming of a magnitude that is 1.5 times or more the global mean value. The Amazon region shows significant warming in both seasons. We also note warming that is less than the global mean over larger parts of the central United States, which disappears at GWT $=4^{\circ} \mathrm{C}$. Much of the Indian subcontinent also shows warming that is less than the global mean at each GWT. These results are largely consistent with local or regional changes seen using pattern scaling approaches (Tebaldi and Arblaster 2014; Tebaldi and Knutti 2018).

If we look at regional changes going from GWT $=2^{\circ}$ to $4^{\circ} \mathrm{C}$ (Fig. 9), the pattern of warming seen at GWT $=2^{\circ} \mathrm{C}$ is further reinforced. Almost all parts of the world show an increase in warming going from $2^{\circ} \mathrm{C}$ and, once again, the high warming regions are in the high northern latitudes (by about $6^{\circ} \mathrm{C}$ in DJF and between $4^{\circ}$ and $5^{\circ} \mathrm{C}$ in $\mathrm{JJA}$ ), around $3^{\circ}-4^{\circ} \mathrm{C}$ in western Europe and the Mediterranean and parts of the Amazon. This suggests than at a GWT of $4^{\circ} \mathrm{C}$, winter warming over the extreme northern land regions may reach as much as $12^{\circ} \mathrm{C}$. The tropics are also seen to warm by a similar amount in going from $2^{\circ}$ to $4^{\circ} \mathrm{C}$ as for $\mathrm{GWT}=2^{\circ} \mathrm{C}$, although by a smaller magnitude than that seen in higher and midlatitudes. Overall there is a clear scaling up of regional temperatures as we go to higher thresholds. Regions where the second $2^{\circ} \mathrm{C}$ of warming is greater than the first include Siberia and Alaska in JJA and the northern United States in DJF.

\section{1) SIGNIFICANCE OF WARMING SIGNAL}

To establish the significance of the identified regional warming at different GWTs we quantify these changes with respect to the internal climate variability of that region and refer to this as a forced climate change signal-to-noise ratio. Different methods have been proposed to identify if a forced change is significant compared to interannual variability, including when examining emerging warming trends in observed data (Mahlstein et al. 2012; Hawkins et al. 2020; King et al. 2018). We characterize this signal-to-noise ratio (or emerging signal) by looking at future changes in temperature expressed as a fraction of internal variability (defined as the annual or seasonal standard deviation in surface temperature of 1100 years of the UKESM1 pi-Control experiment). The 21-yr mean warming at GWT $=2^{\circ}$ and $4^{\circ} \mathrm{C}$ are expressed as a fraction of this 1-yr pi-Control standard deviation (Fig. 10). For the high northern latitudes in winter, the amount of mean warming seen at GWT $=2{ }^{\circ} \mathrm{C}$ is of a similar magnitude to the unforced annual standard deviation of temperatures in this region but at $\mathrm{GWT}=4^{\circ} \mathrm{C}$ it is $2-3$ times the interannual standard deviation. This "signal-to-noise" estimate highlights extensive areas of tropical land where the relatively modest absolute warming signal seen in Fig. 8 at GWT $=2^{\circ}$ and $4^{\circ} \mathrm{C}$ is significant when compared to the model's internal temperature variability over 

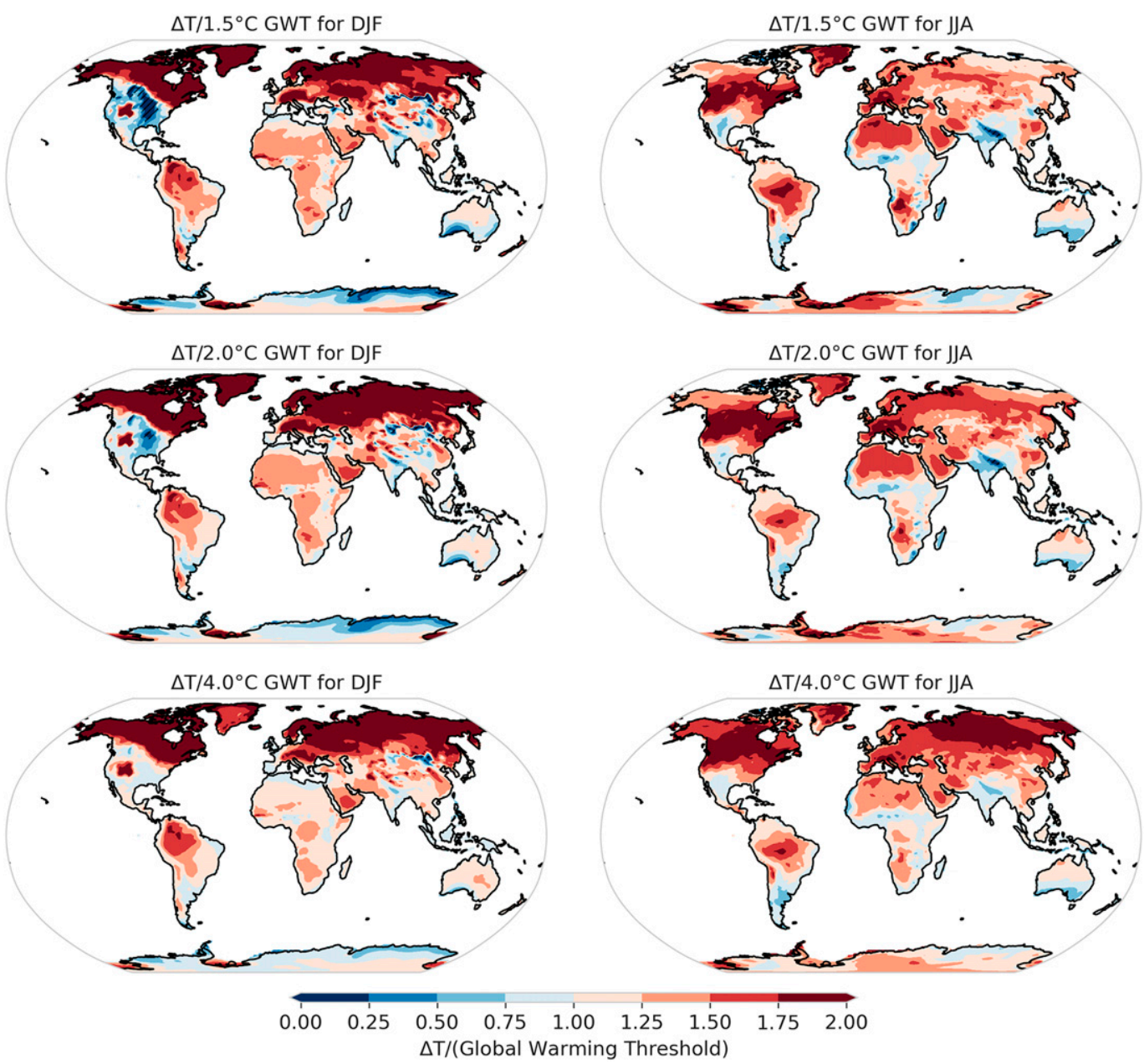

FIG. 8. Seasonal surface temperature anomalies normalized by the global mean for (left) DJF and (right) JJA at GWTs $1.5^{\circ}, 2^{\circ}$, and $4^{\circ} \mathrm{C}$. The ratio of $21-\mathrm{yr}$ means temperature change around the year of exceedance of a given threshold to the global mean temperature, calculated as an ensemble mean for UKESM1 SSP3-7.0.

these regions. It is important to note that the forced warming signal will be in addition to any future internal variability and even relatively modest absolute warming over tropical land regions can take the climate of these regions outside what is expected from year-to-year temperature variability.

\section{2) LAND VERSUS OCEAN WARMING}

We next look at the land-ocean differences in warming and calculate a latitudinal land-ocean warming ratio obtained by dividing the zonal mean surface temperature changes over land by the zonal mean warming over the oceans. To avoid latitudes that are largely oceanic, we focus our analysis of land/ocean warming in the region $50^{\circ} \mathrm{S}-65^{\circ} \mathrm{N}$ and continue using the SSP3-7.0 ensemble in Fig. 11. The annual mean warming ratio ranges between 1 and 2 and remains more or less constant with increasing GWTs. Relative maxima are seen in the land warming ratio over subtropical land regions of both hemispheres. JJA and DJF warming patterns are similar in that the ratio is smaller near the equator and increases moving toward the subtropics but the ratio is lower in
JJA (1.2) than in DJF (1.5). The excess warming in subtropical land regions is consistent with a drying surface and soil layer leading to an increased amount of incoming energy going into sensible heating (warming) as opposed to evaporation. The relatively smaller warming amplification in JJA seen in the subtropical Northern Hemisphere compared to DJF warming in the Southern Hemisphere subtropics is likely associated with increased rainfall in the Indian monsoon.

\section{3) Polar amplification}

Figure 12 shows the change in sea ice percentage area at its seasonal minimum along with summer polar temperature change and changes in sea ice at its seasonal maximum along with winter polar temperature change with increasing GWT (see figure caption for details). Also displayed as diagonal lines in Fig. 12 is the polar warming amplification (PA), defined here as the ratio of warming poleward of $66^{\circ}$ latitude relative to global warming. $\mathrm{PA}$ is a major signal at all GWTs seen in the zonal as well as spatial mean figures. UKESM1 simulations show that the maximum PA occurs in winter with 


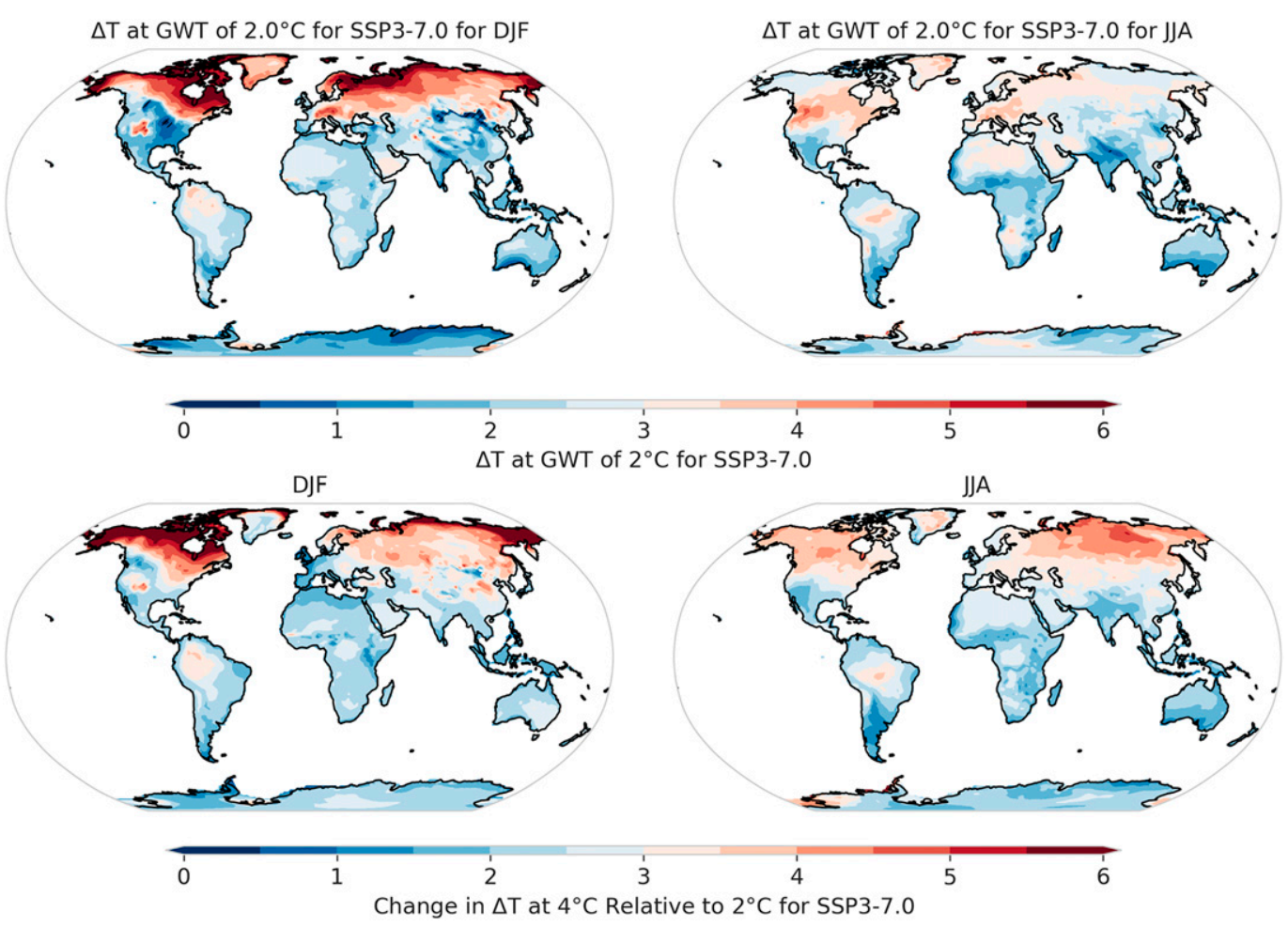

FIG. 9. Surface temperature changes at $2^{\circ} \mathrm{C}$ warming contrasted with a doubling at $4^{\circ} \mathrm{C}$. (top) The 21 -yr ensemble mean of surface temperature warming centered around the year of exceedance; (bottom) as in the top row, but now relative to $2^{\circ} \mathrm{C}$ from UKESM1 SSP3-7.0.

an amplification in the Arctic that is up to 4 times the global mean for $\mathrm{GWT}=5^{\circ} \mathrm{C}$ (Fig. 12b). This warming amplification coincides with rapid and accelerating ice area loss as GWT increases with around $50 \%$ loss relative to preindustrial levels at $\mathrm{GWT}=5^{\circ} \mathrm{C}$. The summer sea ice reduction in the Arctic reaches $70 \%$ by $\mathrm{GWT}=2^{\circ} \mathrm{C}$ and the Arctic is essentially ice free in the summer by $\mathrm{GWT}=3^{\circ} \mathrm{C}$ with a corresponding PA also increasing up to about 1.5. It is worth noting that the Arctic does not become completely sea ice free at GWT $=2{ }^{\circ} \mathrm{C}$. A smaller, steadier rate of ice loss in the Antarctic is accompanied by a warming lower than the global mean in the summer and about 1.5 times global mean warming in winter.

\section{d. Changes in the water cycle}

Changes in the regional water cycle will have important impacts on societies and ecosystems such as those assessed by the reports from the IPCC Working Group II for Impacts, Adaptation and Vulnerability. Here we focus on large-scale diagnostics of water cycle change, considering precipitation, precipitation minus evaporation $(P-E)$, and soil moisture. Figure 13 shows the absolute changes in zonal mean precipitation and $(P-E)$ over land regions. Annual and DJF precipitation changes are mostly positive in the Northern Hemisphere with the largest peaks occurring in JJA season between $5^{\circ}$ and $15^{\circ} \mathrm{N}$ coincident with the ascending branch of the intertropical convergence zone (ITCZ) and around the Tropic of Cancer $\left(23.5^{\circ} \mathrm{N}\right)$. The negative deviation in precipitation and $(P-E)$ seen in JJA season is coincident with the descending branch of the Hadley cell. The magnitude of precipitation changes increases with increasing warming thresholds. In the Southern Hemisphere, decreases in annual precipitation in the subtropics and increases at higher latitudes become larger with warming thresholds. Similar patterns are seen for annual $(P-E)$. The significant spike in JJA rainfall between approximately $5^{\circ}$ and $15^{\circ} \mathrm{N}$ can be largely attributed to a stronger Indian monsoon, as well increases over the Sahel region and the North American monsoon (Fig. 14c) that are broadly consistent with CMIP5 projections in Menon et al. (2013).

Figure 14 shows the changes in three variables related to the water cycle: precipitation, $P-E$, and soil moisture at $2^{\circ}$ and $4^{\circ}$ warming for UKESM1. We see an increase in monsoon precipitation over the Indian subcontinent of about $25 \%-$ $50 \%$ at $2^{\circ} \mathrm{C}$ warming and a further increase by a similar amount at a GWT of $4^{\circ} \mathrm{C}$. Rainfall over the Sahel is projected to increase by about $25 \%-50 \%$ at $2{ }^{\circ} \mathrm{C}$ warming and further increases in some areas $(75 \%$ to $>100 \%)$ as the global mean doubles in UKESM1. Except for parts of western Africa, this region shows an increase in all three variables (Dunning et al. 2018; Monerie et al. 2020), although it is important to note that these are percent changes in precipitation in a region that experiences quite low rainfall today.

Central America has an emerging drying signal in the JJA season in the future. Figure 14 shows that this region sees a substantial reduction in $P-E$ at $2^{\circ}$ and $4^{\circ} \mathrm{C}$ and a corresponding decrease in soil moisture (doubling from a $12.5 \%$ to $25 \%$ decrease). The Mediterranean region has been identified 

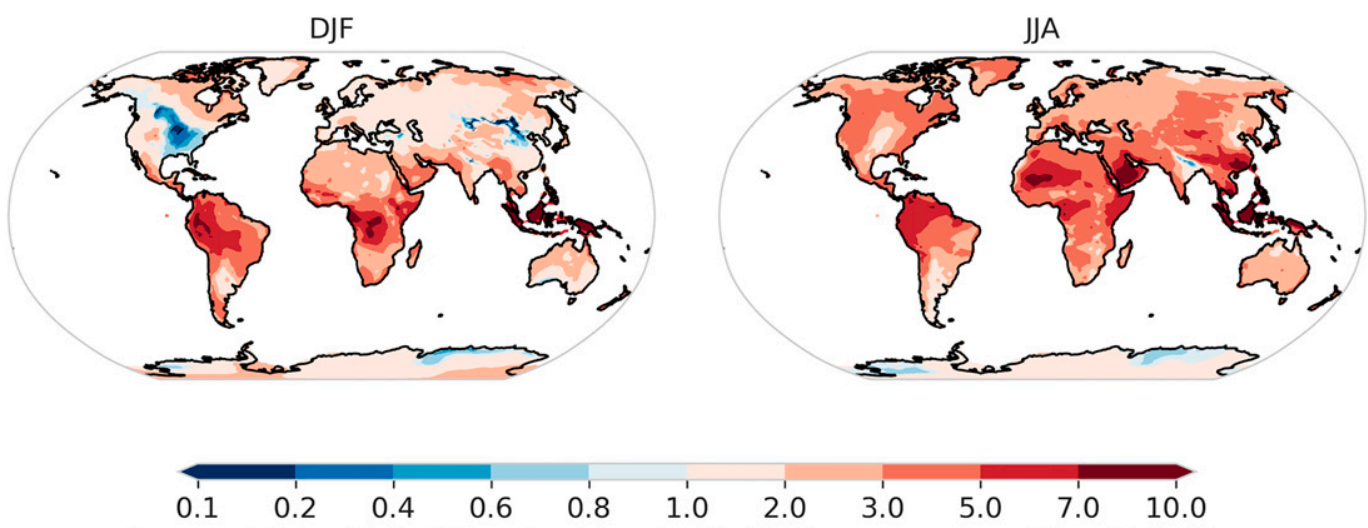

Seasonal $\Delta \mathrm{T}$ at Global Warming Threshold of $2{ }^{\circ} \mathrm{C}$ as a fraction of 1-yr PI StdDev
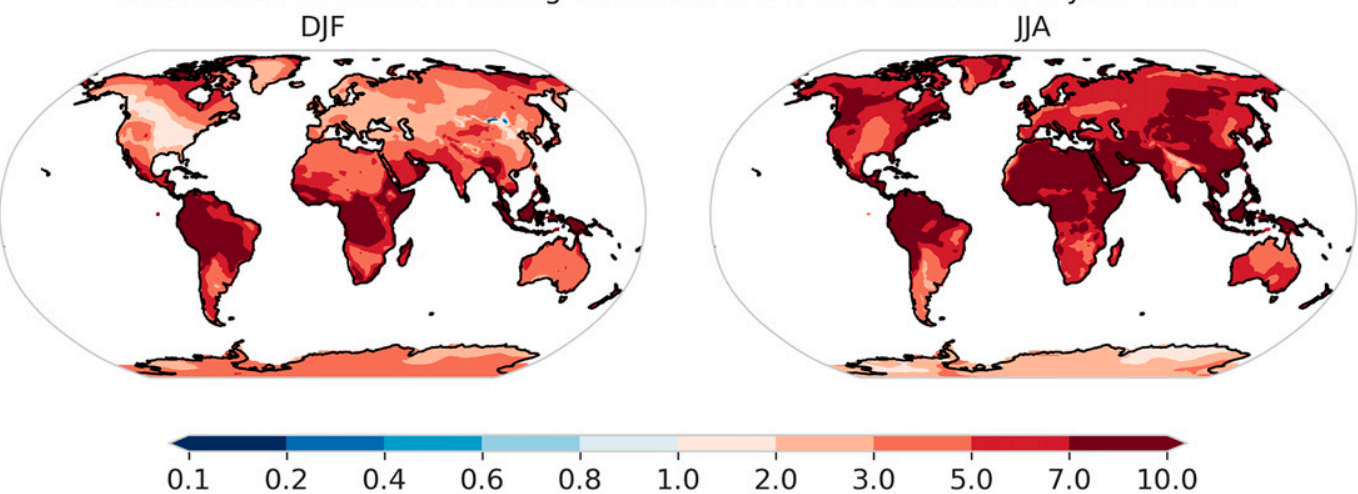

Seasonal $\Delta \mathrm{T}$ at Global Warming Threshold of $4^{\circ} \mathrm{C}$ as a fraction of 1-yr PI StdDev

FIG. 10. Changes in global spatial temperature patterns at GWTs of (top) $2^{\circ}$ and (bottom) $4^{\circ} \mathrm{C}$ plotted with reference to pi-Control simulation data. The 21-yr mean change in surface temperature around threshold exceedance years is expressed as a fraction of the 1-yr pi-Control standard deviation to show its significance compared to natural climate variability. We show the average for UKESM1 SSP3-7.0 ensemble members.

as a climate change "hotspot" in the future from the perspective of potential impacts on a range of activities in the region (Giorgi 2006). UKESM1 projections (see Fig. 15) indicate a reduction in JJA precipitation between $25 \%$ and $50 \%$ in the region at $\mathrm{GWT}=2^{\circ} \mathrm{C}$ and a further amplification of $50 \%-75 \%$ at $4^{\circ} \mathrm{C}$, with important decreases in soil moisture. Other areas that also show a reduction in soil moisture in the JJA season are the southeastern Amazon region, southern Africa, and Australia. This drying signal is also seen more widely in CMIP5 and CMIP6 simulations including UKESM1 (Wainwright et al. 2021).

The annual zonal mean precipitation in Fig. 13 also shows a dip in the Southern Hemisphere which is indicative of a decrease in rainfall in the southern tropics. In the DJF season, precipitation in the Amazon decreases by up to $25 \%$ at $2^{\circ} \mathrm{C}$ and $50 \%$ at $4^{\circ} \mathrm{C}$ compared to the $1850-1900$ period (Fig. 15, top panels). The southern edge of this drying region also emerges as a significant signal outside the simulated internal variability, as seen in the spatial distribution of $P-E$.

\section{Discussion}

In this section, we analyze some of the regional climate changes highlighted earlier and, where possible, suggest a likely cause for the changes seen. A complete understanding of the driving mechanisms for each regional change is beyond the scope of this study.

\section{a. Polar amplification}

The zonal and spatial analysis show there is a clear warming amplification toward the poles, with an increase in the size of this amplification as the GWT threshold increases. Arctic warming is tightly coupled to the loss of sea ice as warming increases and we see that in UKESM1 projections (Fig. 12b), summer sea ice almost completely disappears at $\mathrm{GWT}=3^{\circ} \mathrm{C}$, in agreement with previous studies (Jahn 2018; Niederdrenk and Notz 2018; Screen and Williamson 2017; Sigmond et al. 2018). This sea ice loss increases the area of open ocean (whose albedo is lower than that of the ice) exposed to the atmosphere, resulting in greater ocean heat uptake due to the increased absorption of solar radiation (Serreze et al. 2009; Dai et al. 2019; Screen et al. 2012; Kumar et al. 2010). In the autumn and winter, this heat is released back to the atmosphere resulting in (a) significant winter warming or amplification and (b) thinner winter ice that is liable to melt sooner in the following spring and summer. We observe that the biggest increase in winter polar amplification (PA) occurs over the 

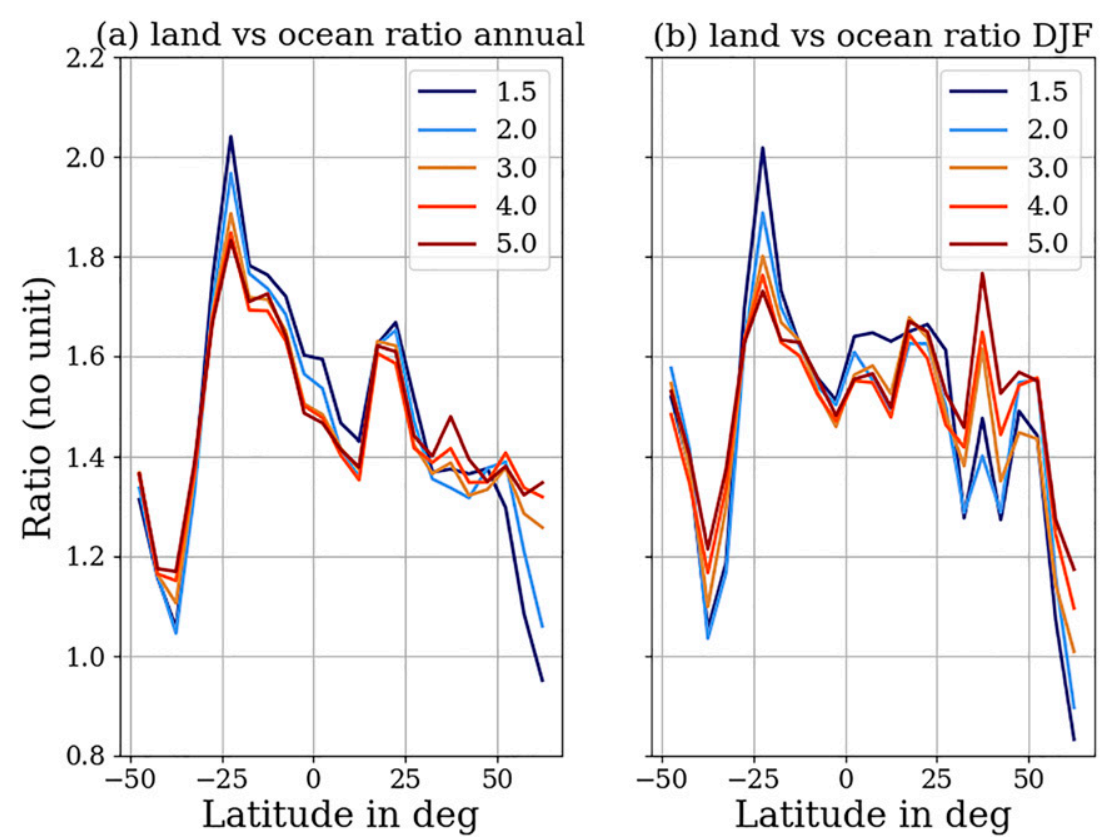

(c) land vs ocean ratio JJA

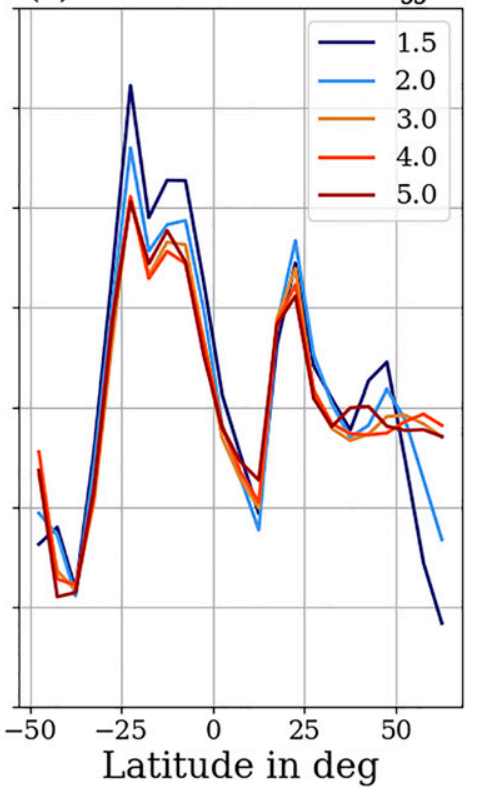

FIG. 11. Ratios of zonal mean changes in land and ocean surface temperature data for annual and the DJF and JJA seasons at different GWTs. Values are plotted for 21-yr ensemble means from UKESM1 SSP3-7.0 experiments around the years of exceedance at different thresholds.

period of rapid summer ice loss between $\mathrm{GWT}=1.5^{\circ} \mathrm{C}$ and $\mathrm{GWT}=3^{\circ} \mathrm{C}$. In the winter, the Arctic retains extensive sea ice cover through to $\mathrm{GWT}=4^{\circ} \mathrm{C}$, beyond which there is a rapid reduction suggesting a shift in the Arctic ice regime to one where multiyear ice is lost and the remaining singleyear ice is thinner and prone to loss through extended periods of the year. The extensive loss of summer sea ice in the Arctic is accompanied by only a modest PA (going from 1 to about 1.2 at $\mathrm{GWT}=3^{\circ} \mathrm{C}$ ) as the majority of excess energy goes into melting ice. In the winter, sea ice loss is less dramatic but the PA is very large, reaching magnitudes of almost 4 times the global mean at $\mathrm{GWT}=4^{\circ} \mathrm{C}$. We see a pattern of time-lagged effect where warming leads to a reduction in sea ice in the summer and amplified warming in winter. An important amplifying process of sea ice loss is the ice albedo effect as mentioned above. The melting of ice in the summer leads to a decreased albedo as darker ocean (albedo $\sim 0.07$ ) is revealed but can also be through the persistence of summer melt ponds (whose albedo is between 0.1 and 0.5 ) on the ice (albedo $\sim 0.6$ for bare ice and $\sim 0.85$ for snow-covered ice) that reduces the overall area averaged albedo of the Arctic (Flocco et al. 2012; Perovich et al. 2007; Nicolaus et al. 2012).

With more of the ocean in the Arctic exposed, increased surface evaporation leads to an increase in atmospheric water vapor, allowing the water vapor feedback to also enhance Arctic warming (Ghatak and Miller 2013). Under high warming thresholds $\left(\mathrm{GWT}=5^{\circ} \mathrm{C}\right)$, mean winter Arctic warming in UKESM1 can reach as high as $20^{\circ} \mathrm{C}$ locally relative to $1850-1900$ values. Thinner sea ice also makes for a thinner insulating layer between the ocean and the overlying atmosphere, allowing increased heat conduction from the ocean through the ice to influence near-surface air temperatures (Serreze and Barry 2011; Lang et al. 2017). In addition, frequent stable boundary layers over the Arctic winter ice mean the warming signal is constrained close to the surface (Screen and Simmonds 2010). The large winter $\mathrm{PA}$ in the Arctic is therefore primarily driven by the large sea ice melt in the summer that changes the thermal conditions at the ocean-ice surface in the subsequent winter. Figures $12 \mathrm{a}$ and $12 \mathrm{~b}$ show the changes in temperature and the sea ice changes for summer and winter respectively. In the winter, air temperatures are too cold to melt ice although ocean warming can contribute and there is a $50 \%$ ice loss at $\mathrm{GWT}=5^{\circ} \mathrm{C}$.

Finally, there is also an interplay with other factors such as changes in cloud cover that can both increase surface warming through increasing downward longwave radiation and have a cooling effect by reflecting shortwave radiation (apart from during winter); the net effect could result in an increase in the warming signal (He et al. 2019; Higgins and Cassano 2009). In UKESM1, we see that the change in JJA net cloud radiative effect in the Arctic is negative (i.e., net cooling) due to more open water and evaporation leading to more clouds accompanied by an increase in liquid water path (we have provided cloud-related variable plots in the online supplemental information for any interested readers). In the winter, the combined warming and evaporation show an increase in the liquid water path which is likely to enhance warming through increased downwelling longwave radiation. Amplification in the Antarctic is smaller than that in the Arctic and is mainly constrained to the area of sea ice cover in 

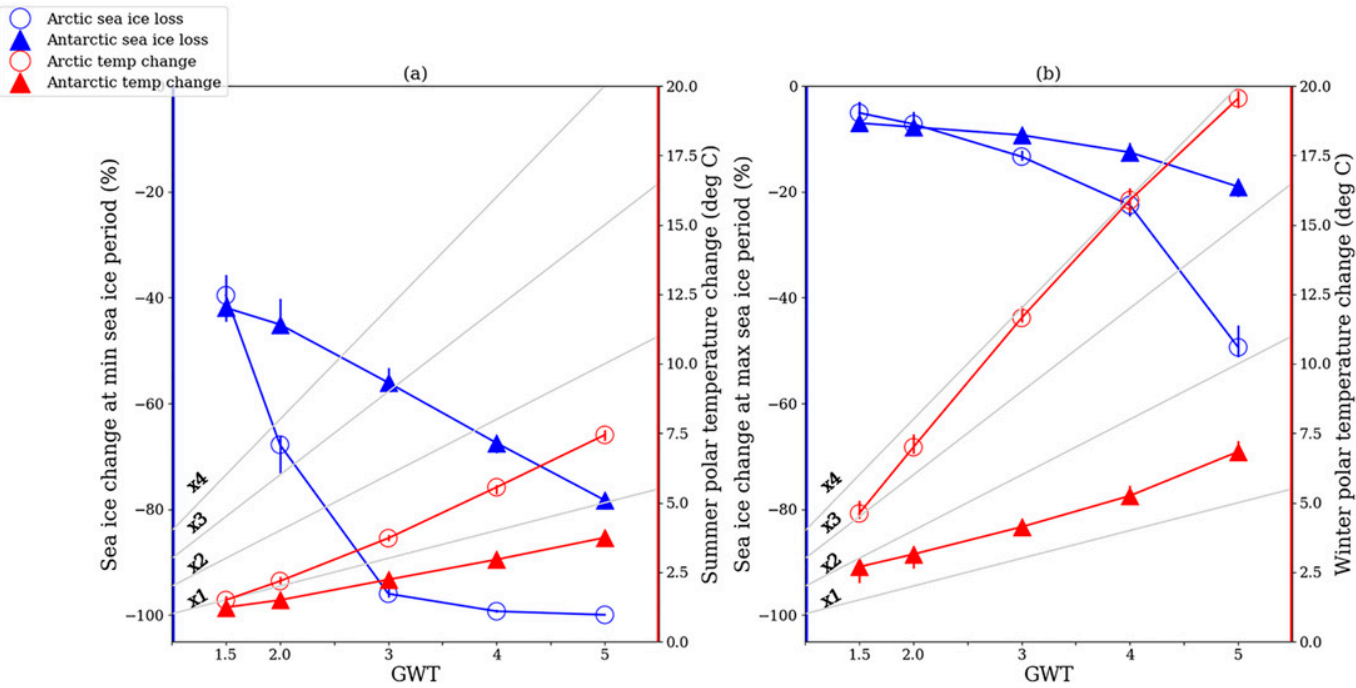

FIG. 12. Polar amplification and sea ice loss at the poles at different warming thresholds. Arctic sea ice loss and temperature changes are shown as red triangles and circles while the respective changes in the Antarctic are in blue. (a) Sea ice change in comparison to 1850-1900 at different GWTs for the minimum sea ice period, which is AugustOctober for the Arctic and February-April for the Antarctic regions, with the corresponding hemisphere's summer temperature change as JJA for the Arctic and DJF for the Antarctic. (b) Sea ice change in comparison to 1850-1900 at different GWTs for the maximum sea ice period, which is February-April for the Arctic and August-October for the Antarctic regions, with the corresponding hemisphere's summer temperature change as JJA for the Arctic and DJF for the Antarctic. In both plots, the polar change in temperature is the spatially averaged mean change in temperature at each GWT from $66.5^{\circ}$ to $90^{\circ} \mathrm{S}$ and from $66.5^{\circ}$ to $90^{\circ} \mathrm{N}$. Light gray lines indicate the magnitude of amplification at the poles as being the same $(\times 1)$, twice $(\times 2), 3$ times $(\times 3)$, or 4 times $(\times 4)$ that of the global mean temperature. Data are shown averaged across all Tier 1 SSPs from UKESM1. Vertical lines through the circle and triangles show the 25th-75th-percentile range.

the historical period. Similar to the Arctic, we do see areas of negative net cloud radiative effects (in the DJF season here), more evaporation with increase in liquid cloud path, and increased cloud cover leading to an increased reflection of solar radiation. Seasonal sea ice changes alongside annual amplification at both poles for a comparison are provided in the online supplemental material for the interested reader.

\section{b. Northern high latitudes}

The large warming seen in higher latitudes of the Northern Hemisphere $\left(>60^{\circ} \mathrm{N}\right)$, including the continental Arctic in $\mathrm{JJA}$, is associated with a large positive net cloud radiative effect that is around $10-12.5 \mathrm{~W} \mathrm{~m}^{-2}$ at $2^{\circ} \mathrm{C}$ and further increases to $15 \mathrm{~W} \mathrm{~m}^{-2}$ at $4^{\circ} \mathrm{C}$. This change is associated with decreased cloud cover and reduced liquid water path, which have been shown to influence warming in this region (Tang and Leng 2012). The decrease in clouds and warming results in decreased precipitation with drying as seen in Fig. 14.

Another factor likely driving warming in this region is snow cover changes influencing the snow-albedo feedback (Serreze et al. 2012; Chapin et al. 2005). A warming amplification occurs through loss of snow cover that 1) decreases surface albedo allowing more shortwave radiation absorption and 2) decreases snow depth, reducing insulation between the soil and air, allowing more efficient conduction of heat from the soil to influence the near surface air temperatures (Déry and Brown 2007). There is a decrease in snow cover of around $9 \%$ (around 2 million $\mathrm{km}^{2}$ ) compared to the $1850-1900$ mean for $2^{\circ} \mathrm{C}$ and double that at $4^{\circ} \mathrm{C}$ for the JJA season. However, small increases seen during DJF of $0.43 \%$ and $0.7 \%$ are likely due to the increase in snow precipitating as discussed. Other feedbacks include vegetation changes (Berg et al. 2016; Swann et al. 2010) and, even though UKESM1 vegetation is dynamically simulated (meaning vegetation can grow and die as a results of simulated climate stress), our analysis of tree fraction changes did not show a significant enough change in vegetation to alter the surface albedo in the region. A further focused regional analysis of the vegetation dynamics in the region is required to make any claims relating changes in vegetation to warming in UKESM1.

\section{c. Mediterranean and eastern Europe}

In the Mediterranean and parts of eastern Europe summer warming is amplified by more than the GWT increase on moving from GWT $=2^{\circ} \mathrm{C}$ to GWT $=4^{\circ} \mathrm{C}$ (see Fig. 8). This warming is collocated with clear decreases in precipitation and soil moisture, both of which will act to dry the surface and shift the surface energy balance from evaporative to being sensible heat dominated (Zampieri et al. 2009; King 2019). In addition, a significant decrease in cloud cover from the $1850-1900$ mean period is seen over this region $(12 \%-$ 
(a) absolute change in annual pr

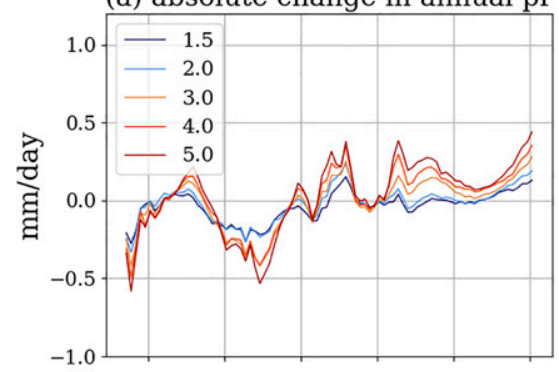

(d) absolute change in annual p-e

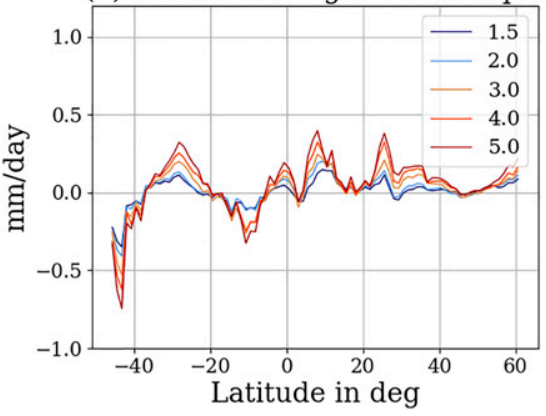

(b) absolute change in djf pr

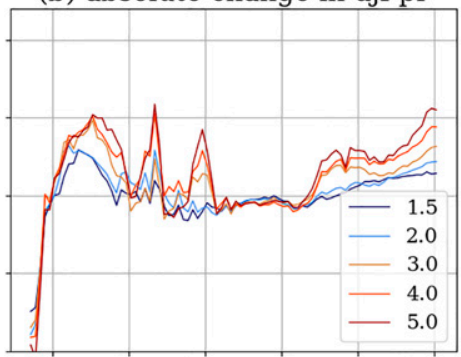

(e) absolute change in djf p-e

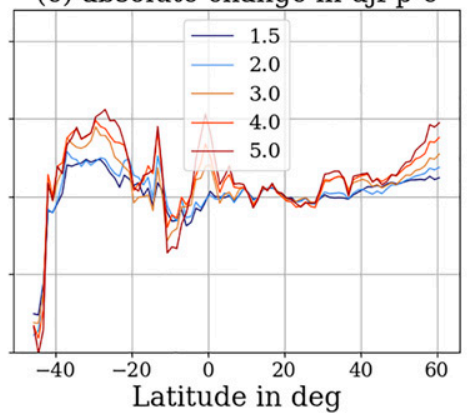

(c) absolute change in jja pr

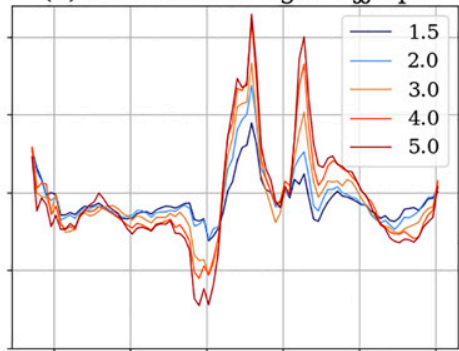

(f) absolute change in jja p-e

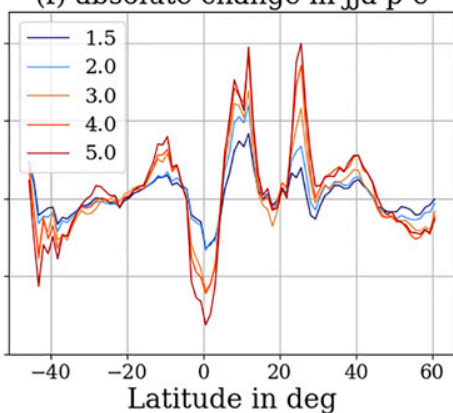

FIG. 13. Changes in precipitation and precipitation minus evaporation $(P-E)$ plotted as 21 -yr zonal mean changes from 1850 to 1900 around years of exceedance at different thresholds. (top) Absolute changes for annual, DJF, and JJA precipitation over land; (bottom) as in the top row, but for changes for precipitation minus evaporation over land. Ensemble means for SSP3-7.0 are plotted for different thresholds.

$15 \%$ and $20 \%$ ), accompanied by a positive net cloud radiative effect (in the range of 15 and $20 \mathrm{~W} \mathrm{~m}^{-2}$, respectively). Reduced cloud cover enhances warming by increasing surface solar radiation and potentially lowers the chances of precipitation thereby further drying soil in addition to the increased atmospheric evaporative demands (Scheff and Frierson 2015).

\section{d. Amazon}

The Amazon region sees warming of between 1 and 1.5 times the global mean depending on the season and the area under consideration. Precipitation and soil moisture changes emerge more clearly on going from $2^{\circ}$ to $4^{\circ} \mathrm{C}$ almost doubling in magnitude, particularly in the southeast Amazon region. This reduction in soil moisture will lead to the surface energy balance being more dominated by sensible heating, contributing to the localized warming. There is a decrease in tree fraction (of between $7 \%$ and $8 \%$ ) with warming, mostly seen as a fracturing of previously treecovered regions. However, the high rate of increase in regional temperature, when combined with other factors such as deforestation (which will be substantial for SSP3-7.0), drought conditions, and heat stress, has the potential to lead to extensive forest loss. Burton et al. (2021) suggest this dieback is likely to be further compounded by fire feedbacks, which are presently not included in UKESM1.

\section{e. Tropics}

Tropical warming is more modest than in polar regions but is substantial when expressed as a fraction of internal variability, estimated as interannual variability in the preindustrial simulation (Fig. 10). Effectively, the time of emergence of this warming signal, which is a certain magnitude greater than preindustrial warming, is earlier for the tropics than higher latitudes (Hawkins and Sutton 2012; Mahlstein et al. 2011). This forced signal will be in addition to natural variability and will exacerbate the risk of climate extremes across the region. The increase in precipitation seen at $0^{\circ} \mathrm{S}$ in DJF and around $10^{\circ} \mathrm{N}$ in JJA suggests an intensification of the ITCZ at its preferred climatological locations, consistent with a trend seen in observations (Wodzicki and Rapp 2016). The counterpart to this is the intensification of the descending branch of the Hadley cell, which is associated with reduced precipitation at $10^{\circ} \mathrm{S}$ in DJF and just north of the tropics in JJA.

\section{f. Indian monsoons}

Summer monsoon (JJA) precipitation over the Indian subcontinent increases with increasing GWTs in UKESM1 simulations, consistent with results seen in similar studies (Chevuturi et al. 2018; Qu and Huang 2019). This increase is associated with cooler temperatures, more negative net cloud radiative effect, and higher cloud liquid water path in the model. Changes in the dynamics of the ITCZ and the energy/moisture budget in the region, both caused by warming have been proposed as mechanisms that lead to an intensification of the Indian monsoon in future projections (Hari et al. 2020; Mamalakis et al. 2021). Further work is required to determine the underlying cause of this intensification in UKESM1. 


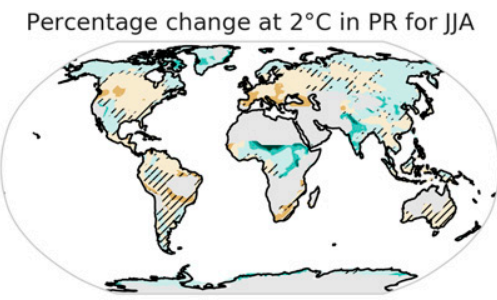

Percentage change at $2^{\circ} \mathrm{C}$ in P-E for JJA

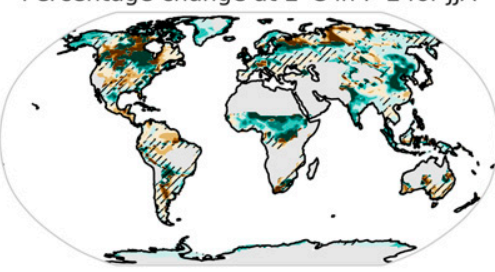

Percentage change at $2^{\circ} \mathrm{C}$ in SM for JJA

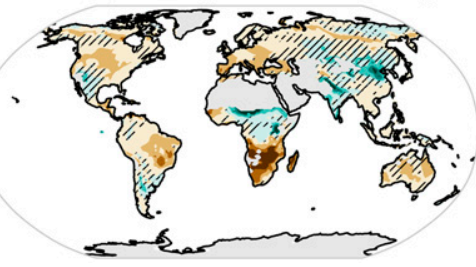

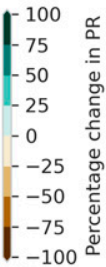
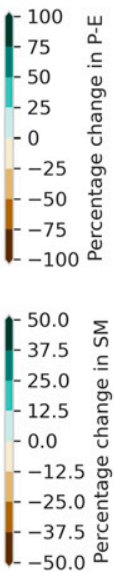

Percentage change at $4^{\circ} \mathrm{C}$ in PR for JJA

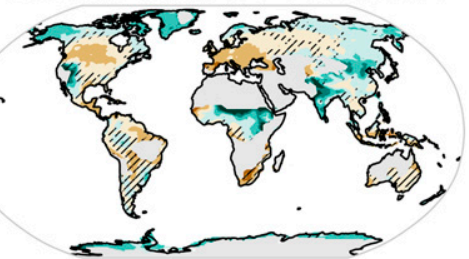

Percentage change at $4^{\circ} \mathrm{C}$ in P-E for JJA

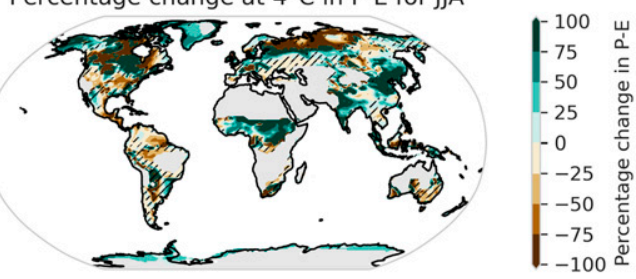

Percentage change at $4^{\circ} \mathrm{C}$ in SM for JJA

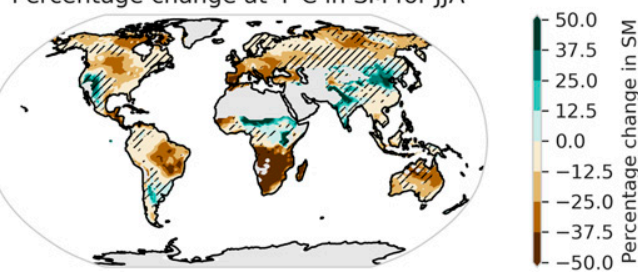

FIG. 14. Spatial changes in key hydrology variables: precipitation, precipitation minus evaporation, and soil moisture at (left) $2^{\circ}$ and (right) $4^{\circ} \mathrm{C}$ warming for JJA. Percentage changes with respect to $1850-1900$ around the year of exceedance are shown for each threshold, averaged across all ensemble members for UKESM1 SSP3-7.0. Grayed-out areas are regions with historically very low values. The hatching is where the magnitude of change is less than natural variability, which is calculated as the standard deviation of 21 -yr climatologies from the pi-Control experiment.

\section{g. Sahel}

In Figs. 11 and 8, we saw that land regions warm more than the ocean with increasing GWTs and that the surface temperatures over the Sahara are consistently higher than the global mean. These two factors have previously been linked to an intensification of the Saharan heat low (SHL; a near-surface thermal low pressure system) resulting in increased Sahel rainfall but with a delay in the season (Haarsma et al. 2005; Dunning et al. 2018). Schewe and Levermann (2017) link increases in sea surface temperatures in the Atlantic and Mediterranean sea to this expansion of the West African monsoon domain and hypothesize that the $1.5^{\circ}-2^{\circ} \mathrm{C} \mathrm{GWT}$ may be a tipping point triggering a transition to a wetter Sahel. Indeed, Dong and Sutton (2015) show that an increase in greenhouse gases in the atmosphere is the main cause for the increase or recovery in Sahelian rainfall, with decreases in Northern Hemisphere aerosol emissions as a secondary driver, and UKESM1 simulations show that the increase is projected to be sustained and even amplified with further warming.

\section{Conclusions}

Global surface temperature data from ScenarioMIP and historical simulations from 32 CMIP6 models indicate that except under a sustainable pathway, specifically SSP1-1.9, global mean warming will exceed $1.5^{\circ} \mathrm{C}$ before the end of the century. Under SSP1-2.6, 20 of the 32 models sampled exceed $2^{\circ} \mathrm{C}$ warming by 2100 . For the scenarios with stronger radiative forcing (SSP3-7.0 and SSP5-8.5), a majority of models exceed $4^{\circ} \mathrm{C}$ global warming, with a small fraction even exceeding $5^{\circ} \mathrm{C}$ warming. The timing of global mean warming threshold exceedance shows a relationship with both the transient climate response (TCR) and effective climate sensitivity (ECS) of the models sampled. UKESM1 has a relatively high ECS and TCR and therefore exceeds the various warming thresholds earlier than the median date of the CMIP6 multimodel ensemble.

We analyzed the ScenarioMIP simulations from UKESM1 to identify key regional climate change signals at different global warming thresholds, including the magnitude and spatial extent of these changes on going from lower to higher warming thresholds. We further discuss some of the physical processes underpinning these changes. In the UKESM1 model, we find the following:

1) The $5^{\circ} \mathrm{C}$ warming threshold is exceeded by the end of the century in SSP3-7.0 and SSP5-8.5 and UKESM1 mean exceedance years almost always occur earlier than the CMIP6 median year.

2) The warming patterns at specific thresholds are not sensitive to the scenario or pathway taken to reach that threshold.

3) A significant Arctic warming amplification is identified, which can be as much as 4 times the global mean warming during DJF season at higher GWTs. Commensurate with 


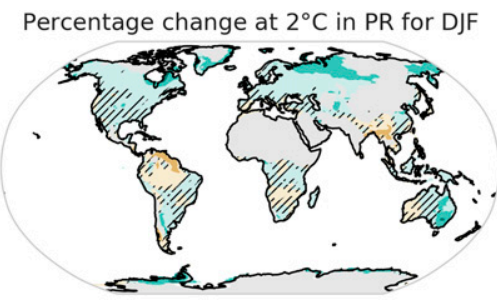

Percentage change at $2^{\circ} \mathrm{C}$ in P-E for DJF

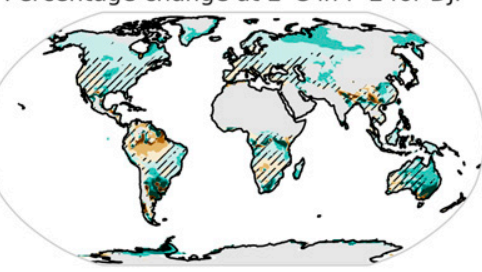

Percentage change at $2^{\circ} \mathrm{C}$ in SM for DJF

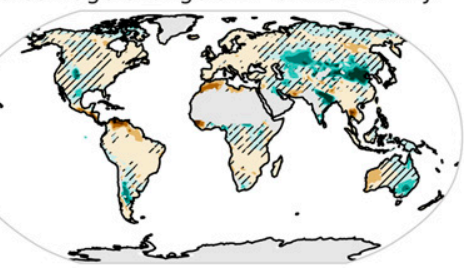

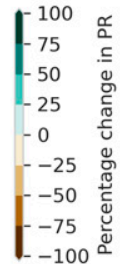
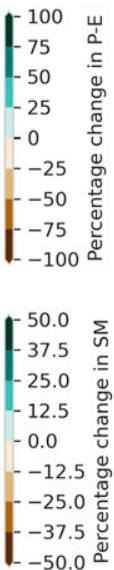

Percentage change at $4^{\circ} \mathrm{C}$ in PR for DJF

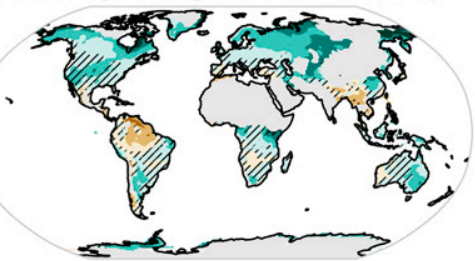

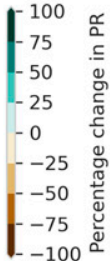

Percentage change at $4^{\circ} \mathrm{C}$ in P-E for DJF
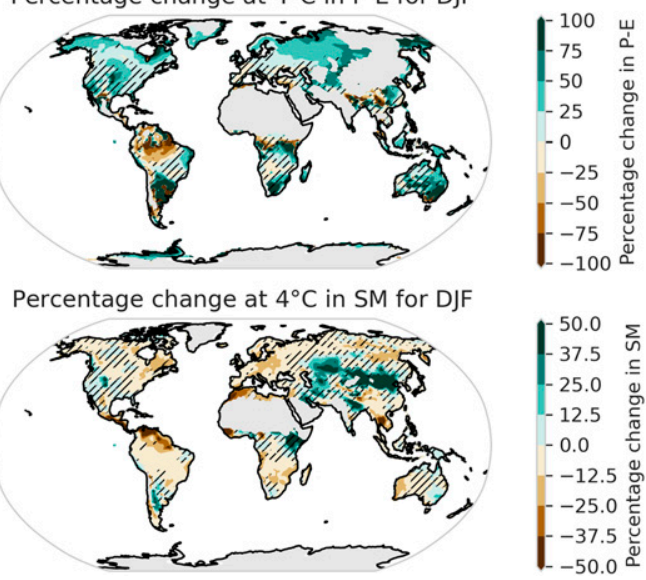

FIG. 15. As in Fig. 14, but for DJF.

the large Arctic warming, sea ice loss is extensive, with the Arctic being essentially ice free in the summer season at a GWT of $3^{\circ} \mathrm{C}$.

4) In addition to the large Arctic amplification, warming in the high Northern Hemisphere land regions is also significant, being twice the global average at all GWTs in the winter (DJF) season and more than 1.5 times the global average in the summer (JJA) season. The seasonal mean warming exceeds the magnitude of interannual variability in the piControl for more than $50 \%$ of this land region by a GWT of $2^{\circ} \mathrm{C}$ and is up to 10 times the pi-Control interannual variability at a GWT of $4^{\circ} \mathrm{C}$ in JJA season. Also for the JJA season, the increase in warming over the northern land regions is greater going from $2^{\circ}$ to $4^{\circ} \mathrm{C}$ global mean warming than the warming seen going from preindustrial values to a GWT of $2^{\circ} \mathrm{C}$ (i.e., there is a local amplification of the warming signal).

5) In a number of regions drier conditions (decreased rainfall and reduced soil moisture) accompany warming. This is particularly the case for subtropical land regions, such as the Mediterranean, Central America, and the Middle East in JJA, where soil moisture values decrease by $\sim 25 \%$ $\left(\mathrm{GWT}=2^{\circ} \mathrm{C}\right)$ to $\sim 40 \%\left(\mathrm{GWT}=4^{\circ} \mathrm{C}\right)$.

6) The Amazon shows warming more than 1.5 times the global mean warming at all GWTs and for both the DJF and JJA seasons. In addition, there is a significant reduction in soil moisture across southeast Amazonia coincident with a decrease in tree cover.

7) Summer monsoon rainfall and $(P-E)$ increases over the Indian subcontinent at both GWT $=2^{\circ}$ and $4^{\circ} \mathrm{C}$. Similarly, JJA rainfall over the Sahel increases, likely related to a stronger west African monsoon.
The regional analysis in this work focused on a single model (UKESM1) so the changes should be viewed as specific to that model. An important next step is to extend our analysis to the CMIP6 multimodel ensemble so we can assess how robust our findings are across different models. This study provides a framework for such an analysis, which we plan to perform in the near future. Our approach can also be used to explore the future likelihood and extent of extreme events and specific regional changes at global warming thresholds such as in Seneviratne et al. (2021) including their potential impacts on society.

Acknowledgments. Authors Swaminathan, Parker, Quaife, and Allan are funded by the U.K. National Centre for Earth Observation (NE/N018079/1). Kelley was supported by the U.K. Natural Environment Research Council through The U.K. Earth System Modelling Project (UKESM, Grant NE/N017951/1). Jones acknowledges funding from the NERC National Capability UKESM Grant NE/N017978/1 and EU Horizon 2020 project CRESCENDO, Grant 641816

Data availability statement. CMIP6 climate model data used in this paper were obtained from the Centre for Data Analysis's (CEDA) Earth System Federation Grid node (https://esgfindex1.ceda.ac.uk/search/cmip6-ceda/).

\section{APPENDIX A}

\section{CMIP6 Models and Corresponding ScenarioMIP Scenarios}

Table A1 provides a list of CMIP6 models and corresponding ScenarioMIP scenarios used in our analysis. 
TABLE A1. List of CMIP6 models and corresponding ScenarioMIP scenarios used in our analysis. We use ensemble member r1 for all models except in the case of UKESM1 as listed.

\begin{tabular}{|c|c|c|c|}
\hline No. & Model & SSP & Ensemble member \\
\hline 1 & UKESM-1-0-LL & $1-1.9,1-2.6,2-4.5,3-7.0,5-8.5$ & $\mathrm{r}\{1-4,8-12,16-19\} \mathrm{i} 1 \mathrm{p} 1 \mathrm{f} 2$ \\
\hline 2 & ACCESS-CM2 & $1-2.6,2-4.5,3-7.0,5-8.5$ & r1i1p1f1 \\
\hline 3 & ACCESS-ESM1-5 & $1-2.6,2-4.5,3-7.0,5-8.5$ & r1i1p1f1 \\
\hline 4 & AWI-CM-1-1-MR & $1-2.6,2-4.5,3-7.0,5-8.5$ & r1i1p1f1 \\
\hline 5 & BCC-CSM2-MR & $1-2.6,2-4.5,3-7.0,5-8.5$ & r1i1p1f1 \\
\hline 6 & CanESM5 & $1-1.9,1-2.6,2-4.5,3-7.0,5-8.5$ & r1i1p2f1 \\
\hline 7 & CESM2 & $1-2.6,2-4.5,3-7.0,5-8.5$ & r4i1p1f1 \\
\hline 8 & CESM2-WACCM & $1-2.6,2-4.5,3-7.0,5-8.5$ & r1i1p1f1 \\
\hline 9 & CIESM & $1-2.6,2-4.5,5-8.5$ & r1i1p1f1 \\
\hline 10 & CMCC-CM2-SR5 & $1-2.6,2-4.5,3-7.0,5-8.5$ & r1i1p1f1 \\
\hline 11 & CMCC-ESM2 & $1-2.6,2-4.5,3-7.0,5-8.5$ & r1i1p1f1 \\
\hline 12 & CNRM-CM6-1-HR & $1-2.6,2-4.5,3-7.0,5-8.5$ & r1i1p1f2 \\
\hline 13 & CNRM-ESM2-1 & $1-1.9,1-2.6,2-4.5,3-7.0,5-8.5$ & r1i1p1f2 \\
\hline 14 & EC-Earth3 & $1-2.6,2-4.5,3-7.0,5-8.5$ & r1i1p1f1 \\
\hline 15 & EC-Earth3-Veg & $1-1.9,1-2.6,2-4.5,3-7.0,5-8.5$ & r1i1p1f1 \\
\hline 16 & FGOALS-f3-L & $1-2.6,2-4.5,3-7.0,5-8.5$ & r1i1p1f1 \\
\hline 17 & FGOALS-g3 & $1-1.9,1-2.6,2-4.5,3-7.0,5-8.5$ & r1i1p1f1 \\
\hline 18 & FIO-ESM-2-0 & $1-2.6,2-4.5,5-8.5$ & r1i1p1f1 \\
\hline 19 & GFDL-ESM4 & $1-1.9,1-2.6,2-4.5,3-7.0,5-8.5$ & r1i1p1f1 \\
\hline 20 & GISS-E2-1-G & $1-1.9,1-2.6,2-4.5,3-7.0,5-8.5$ & r1i1p1f2 \\
\hline 21 & INM-CM4-8 & $1-2.6,2-4.5,3-7.0,5-8.5$ & r1i1p1f1 \\
\hline 22 & IPSL-CM6A-LR & $1-1.9,1-2.6,2-4.5,3-7.0,5-8.5$ & r1i1p1f1 \\
\hline 23 & KACE-1-0-G & $1-2.6,2-4.5,3-7.0,5-8.5$ & r1i1p1f1 \\
\hline 24 & MCM-UA-1-0 & $1-2.6,2-4.5,3-7.0,5-8.5$ & r1i1p1f2 \\
\hline 25 & MIROC6 & $1-1.9,1-2.6,2-4.5,3-7.0,5-8.5$ & r1i1p1f1 \\
\hline 26 & MIROC-ES2L & $1-1.9,1-2.6,2-4.5,3-7.0,5-8.5$ & r1i1p1f2 \\
\hline 27 & MPI-ESM1-2-LR & $1-2.6,2-4.5,3-7.0,5-8.5$ & r1i1p1f1 \\
\hline 28 & MRI-ESM2-0 & $1-1.9,1-2.6,2-4.5,3-7.0,5-8.5$ & r1i1p1f1 \\
\hline 29 & NESM3 & $1-2.6,2-4.5,5-8.5$ & r1i1p1f1 \\
\hline 30 & NorESM2-LM & $1-2.6,2-4.5,3-7.0,5-8.5$ & r1i1p1f1 \\
\hline 31 & NorESM2-MM & $1-2.6,2-4.5,3-7.0,5-8.5$ & r1i1p1f1 \\
\hline 32 & TaiESM1 & $1-2.6,2-4.5,3-7.0,5-8.5$ & r1i1p1f1 \\
\hline
\end{tabular}

\section{APPENDIX B}

\section{Algorithm 1: Global Warming Threshold Exceedance Year Calculation}

Input: $\mathcal{M}$ : set of models; $\mathbf{E n s}_{m}$ : set of ensemble members for $m \in \mathcal{M}$;

SSP: set of SSPs in $\{1-1.9,1-2.6,2-4.5,3-7.0,5-8.5\}$

GWT: set of Global Warming Threshold Temperatures $\{1.5,2.0,3.0,4.0,5.0\}$

GSAT $_{\text {pi }, e}:$ mean value for $1850-1900, \forall e \in \mathbf{E n s}_{m}, \quad m \in \mathcal{M}$;

GSAT $_{\text {hist }, e}:$ list of annual means for 2000-2014, $\forall e \in$ $\mathbf{E n s}_{m}, m \in \mathcal{M}$;

GSAT $_{\mathrm{ssp}, e}$ : list of annual means for 2015-2100, $\forall \mathrm{ssp} \in \mathbf{S S P}, e \in \mathbf{E n s}_{m}, \quad m \in \mathcal{M}$.

Output: GWT_Year $_{\text {gwt,ssp }, e}, \quad \forall$ gwt $\in$ GWT, ssp $\in$ SSP,$\quad e \in$ $\mathbf{E n s}_{m}, m \in \mathcal{M}$.

foreach $m \in \mathcal{M}$ do

foreach $e \in \mathbf{E N S}_{m}$ do

foreach $\operatorname{ssp} \in$ SSP do

$\mathbf{G S A T}_{\text {hist }+ \text { ssp }, e}=\mathbf{G S A T}_{\text {hist }} \cup \mathbf{G S A T}_{\mathrm{ssp}, e}$

Centered_Means $\mathrm{hist}_{\mathrm{hsp}, e}=21$-year centered means for years 2010-2090.

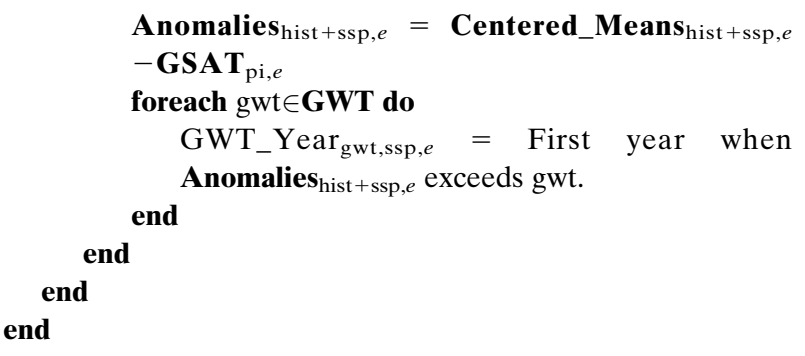

\section{REFERENCES}

Andela, B., and Coauthors, 2021a: ESMValCore. Zenodo, https:// doi.org/10.5281/zenodo.4525749.

—_, and Coauthors, 2021b: ESMValTool. Zenodo, https://doi.org/ 10.5281/zenodo.4562215

Andrews, T., and Coauthors, 2019: Forcings, feedbacks, and climate sensitivity in HadGEM3-GC3.1 and UKESM1. $J$. Adv. Model. Earth Syst., 11, 4377-4394, https://doi.org/10.1029/ 2019MS001866.

Berg, A., and Coauthors, 2016: Land-atmosphere feedbacks amplify aridity increase over land under global warming. Nat. Climate Change, 6, 869-874, https://doi.org/10.1038/ nclimate3029. 
Burton, C., D. Kelley, C. Jones, R. Betts, M. Cardoso, and L. Anderson, 2021: South American fires and their impacts on ecosystems increase with continued emissions. Roy. Meteor. Soc., https://doi.org/10.1002/cli2.8, in press.

Chapin, F. S., and Coauthors, 2005: Role of land-surface changes in Arctic summer warming. Science, 310, 657-660, https://doi.org/ 10.1126/science. 1117368 .

Chen, D., and Coauthors, 2021: Framing, context, and methods. Climate Change 2021: The Physical Science Basis, P. Z. V. Masson-Delmotte et al., Eds., Cambridge University Press, https://www.ipcc.ch/ report/sixth-assessment-report-working-group-i/, in press.

Chevuturi, A., N. P. Klingaman, A. G. Turner, and S. Hannah, 2018: Projected changes in the Asian-Australian monsoon region in $1.5^{\circ} \mathrm{C}$ and $2.0^{\circ} \mathrm{C}$ global-warming scenarios. Earth's Future, 6, 339-358, https://doi.org/10.1002/2017EF000734.

Dai, A., D. Luo, M. Song, and J. Liu, 2019: Arctic amplification is caused by sea-ice loss under increasing $\mathrm{CO}_{2}$. Nat. Commun., 10, 121, https://doi.org/10.1038/s41467-018-07954-9.

Déry, S. J., and R. D. Brown, 2007: Recent Northern Hemisphere snow cover extent trends and implications for the snow-albedo feedback. Geophys. Res. Lett., 34, L22504, https://doi.org/ 10.1029/2007GL031474.

Dong, B., and R. Sutton, 2015: Dominant role of greenhouse-gas forcing in the recovery of Sahel rainfall. Nat. Climate Change, 5, 757-760, https://doi.org/10.1038/nclimate2664.

Dunning, C. M., E. Black, and R. P. Allan, 2018: Later wet seasons with more intense rainfall over Africa under future climate change. J. Climate, 31, 9719-9738, https://doi.org/10.1175/JCLI-D-18-0102.1.

Eyring, V., S. Bony, G. A. Meehl, C. A. Senior, B. Stevens, R. J. Stouffer, and K. E. Taylor, 2016: Overview of the Coupled Model Intercomparison Project Phase 6 (CMIP6) experimental design and organization. Geosci. Model Dev., 9, 19371958, https://doi.org/10.5194/gmd-9-1937-2016.

Flocco, D., D. Schroeder, D. L. Feltham, and E. C. Hunke, 2012: Impact of melt ponds on Arctic sea ice simulations from 1990 to 2007. J. Geophys. Res., 117, C09032, https://doi.org/10.1029/ 2012JC008195.

Ghatak, D., and J. Miller, 2013: Implications for Arctic amplification of changes in the strength of the water vapor feedback. J. Geophys. Res. Atmos., 118, 7569-7578, https://doi.org/ 10.1002/jgrd.50578.

Giorgi, F., 2006: Climate change hot-spots. Geophys. Res. Lett., 33, L08707, https://doi.org/10.1029/2006GL025734.

Haarsma, R. J., F. M. Selten, S. L. Weber, and M. Kliphuis, 2005: Sahel rainfall variability and response to greenhouse warming. Geophys. Res. Lett., 32, L17702, https://doi.org/10.1029/ 2005 GL023232.

Hari, V., G. Villarini, S. Karmakar, L. J. Wilcox, and M. Collins, 2020: Northward propagation of the intertropical convergence zone and strengthening of Indian summer monsoon rainfall. Geophys. Res. Lett., 47, e2020GL089823, https:// doi.org/10.1029/2020GL089823.

Harrington, L. J., D. J. Frame, E. M. Fischer, E. Hawkins, M. Joshi, and C. D. Jones, 2016: Poorest countries experience earlier anthropogenic emergence of daily temperature extremes. Environ. Res. Lett., 11, 055007, https://doi.org/10.1088/1748-9326/11/5/055007.

$\longrightarrow,-$, A. D. King, and F. E. Otto, 2018: How uneven are changes to impact-relevant climate hazards in a $1.5^{\circ} \mathrm{C}$ world and beyond? Geophys. Res. Lett., 45, 6672-6680, https:// doi.org/10.1029/2018GL078888.

Hauser, M., F. Engelbrecht, and E. M. Fischer, 2019: Transient warming levels for CMIP5 and CMIP6. Zenodo, https:// doi.org/10.5281/zenodo.3591807.
Hawkins, E., and R. Sutton, 2009: The potential to narrow uncertainty in regional climate predictions. Bull. Amer. Meteor. Soc., 90, 1095-1108, https://doi.org/10.1175/2009BAMS2607.1.

—_, and — 2012: Time of emergence of climate signals. Geophys. Res. Lett., 39, L01702, https://doi.org/10.1029/ 2011 GL050087.

— edented climates. Nature, 511, E3-E5, https://doi.org/10.1038/ nature13523.

- - and Coauthors, 2017: Estimating changes in global temperature since the preindustrial period. Bull. Amer. Meteor. Soc., 98, 1841-1856, https://doi.org/10.1175/BAMS-D-16-0007.1.

- D. Frame, L. Harrington, M. Joshi, A. King, M. Rojas, and R. Sutton, 2020: Observed emergence of the climate change signal: From the familiar to the unknown. Geophys. Res. Lett., 47, e2019GL086259, https://doi.org/10.1029/2019GL086259.

He, M., Y. Hu, N. Chen, D. Wang, J. Huang, and K. Stamnes, 2019: High cloud coverage over melted areas dominates the impact of clouds on the albedo feedback in the Arctic. Sci. Rep., 9, 9529, https://doi.org/10.1038/s41598-019-44155-w.

Herger, N., B. M. Sanderson, and R. Knutti, 2015: Improved pattern scaling approaches for the use in climate impact studies. Geophys. Res. Lett., 42, 3486-3494, https://doi.org/10.1002/ 2015GL063569.

Higgins, M. E., and J. J. Cassano, 2009: Impacts of reduced sea ice on winter Arctic atmospheric circulation, precipitation, and temperature. J. Geophys. Res., 114, D16107, https://doi.org/ 10.1029/2009JD011884.

Hoegh-Guldberg, O., and Coauthors, 2018: Impacts of $1.5^{\circ} \mathrm{C}$ global warming on natural and human systems. Global Warming of $1.5^{\circ} \mathrm{C}$, IPCC Special Report, 175-311, https://www.ipcc.ch/site/ assets/uploads/sites/2/2019/02/SR15_Chapter3_Low_Res.pdf.

Huang, J., H. Yu, A. Dai, Y. Wei, and L. Kang, 2017: Drylands face potential threat under $2^{\circ} \mathrm{C}$ global warming target. Nat. Climate Change, 7, 417-422, https://doi.org/10.1038/nclimate3275.

Iturbide, M., and Coauthors, 2021: Repository supporting the implementation of FAIR principles in the IPCC-WGI Atlas. Zenodo, https://doi.org/10.5281/zenodo.3691645; https:// github.com/IPCC-WG1/Atlas.

Jacob, D., and Coauthors, 2018: Climate impacts in Europe under $+1.5^{\circ} \mathrm{C}$ global warming. Earth's Future, 6, 264-285, https://doi.org/10.1002/2017EF000710.

Jahn, A., 2018: Reduced probability of ice-free summers for $1.5^{\circ} \mathrm{C}$ compared to $2^{\circ} \mathrm{C}$ warming. Nat. Climate Change, 8, 409-413, https://doi.org/10.1038/s41558-018-0127-8.

Joshi, M., E. Hawkins, R. Sutton, J. Lowe, and D. Frame, 2011: Projections of when temperature change will exceed $2^{\circ} \mathrm{C}$ above pre-industrial levels. Nat. Climate Change, 1, 407-412, https://doi.org/10.1038/nclimate1261.

King, A. D., 2019: The drivers of nonlinear local temperature change under global warming. Environ. Res. Lett., 14, 064005 , https://doi.org/10.1088/1748-9326/ab1976.

- D. J. Karoly, and B. J. Henley, 2017: Australian climate extremes at $1.5^{\circ} \mathrm{C}$ and $2^{\circ} \mathrm{C}$ of global warming. Nat. Climate Change, 7, 412-416, https://doi.org/10.1038/nclimate3296.

- , R. Knutti, P. Uhe, D. M. Mitchell, S. C. Lewis, J. M. Arblaster, and N. Freychet, 2018: On the linearity of local and regional temperature changes from $1.5^{\circ} \mathrm{C}$ to $2^{\circ} \mathrm{C}$ of global warming. J. Climate, 31, 7495-7514, https://doi.org/10.1175/ JCLI-D-17-0649.1.

Kumar, A., and Coauthors, 2010: Contribution of sea ice loss to Arctic amplification. Geophys. Res. Lett., 37, L21701, https:// doi.org/10.1029/2010GL045022. 
Lang, A., S. Yang, and E. Kaas, 2017: Sea ice thickness and recent Arctic warming. Geophys. Res. Lett., 44, 409-418, https:// doi.org/10.1002/2016GL071274.

Lee, J. Y., and Coauthors, 2021: Future global climate: Scenariobased projections and near-term information. Climate Change 2021: The Physical Science Basis, P. Z. V. Masson-Delmotte et al., Eds., Cambridge University Press, https://www.ipcc.ch/ report/sixth-assessment-report-working-group-i/, in press.

Lenton, T. M., J. Rockström, O. Gaffney, S. Rahmstorf, K. Richardson, W. Steffen, and H. J. Schellnhuber, 2019: Climate tipping points-Too risky to bet against. Nature, 575, 592-595, https://doi.org/10.1038/d41586-019-03595-0.

Mahlstein, I., R. Knutti, S. Solomon, and R. W. Portmann, 2011: Early onset of significant local warming in low latitude countries. Environ. Res. Lett., 6, 034009, https://doi.org/10.1088/ 1748-9326/6/3/034009.

— , G. Hegerl, and S. Solomon, 2012: Emerging local warming signals in observational data. Geophys. Res. Lett., 39, L21711, https://doi.org/10.1029/2012GL053952.

Mamalakis, A., and Coauthors, 2021: Zonally contrasting shifts of the tropical rain belt in response to climate change. Nat. Climate Change, 11, 143-151, https://doi.org/10.1038/s41558-020-00963-x.

Meehl, G. A., C. A. Senior, V. Eyring, G. Flato, J.-F. Lamarque, R. J. Stouffer, K. E. Taylor, and M. Schlund, 2020: Context for interpreting equilibrium climate sensitivity and transient climate response from the CMIP6 Earth system models. Sci. Adv., 6, eaba1981, https://doi.org/10.1126/sciadv.aba1981.

Menon, A., A. Levermann, J. Schewe, J. Lehmann, and K. Frieler, 2013: Consistent increase in Indian monsoon rainfall and its variability across CMIP-5 models. Earth Syst. Dyn., 4, 287300, https://doi.org/10.5194/esd-4-287-2013.

Monerie, P.-A., C. M. Wainwright, M. Sidibe, and A. A. Akinsanola, 2020: Model uncertainties in climate change impacts on Sahel precipitation in ensembles of CMIP5 and CMIP6 simulations. Climate Dyn., 55, 1385-1401, https:// doi.org/10.1007/s00382-020-05332-0.

Moss, R. H., and Coauthors, 2010: The next generation of scenarios for climate change research and assessment. Nature, 463, 747756, https://doi.org/10.1038/nature08823.

Nicolaus, M., C. Katlein, J. Maslanik, and S. Hendricks, 2012: Changes in Arctic sea ice result in increasing light transmittance and absorption. Geophys. Res. Lett., 39, L24501, https:// doi.org/10.1029/2012GL053738.

Niederdrenk, A. L., and D. Notz, 2018: Arctic sea ice in a $1.5^{\circ} \mathrm{C}$ warmer world. Geophys. Res. Lett., 45, 1963-1971, https:// doi.org/10.1002/2017GL076159.

Nikulin, G., and Coauthors, 2018: The effects of 1.5 and 2 degrees of global warming on Africa in the CORDEX ensemble. Environ. Res. Lett., 13, 065003, https://doi.org/10.1088/17489326/aab1b1.

O’Neill, B. C., E. Kriegler, K. Riahi, K. L. Ebi, S. Hallegatte, T. R. Carter, R. Mathur, and D. P. van Vuuren, 2014: A new scenario framework for climate change research: The concept of shared socioeconomic pathways. Climatic Change, 122, 387400, https://doi.org/10.1007/s10584-013-0905-2.

_ Project (ScenarioMIP) for CMIP6. Geosci. Model Dev., 9, 3461-3482, https://doi.org/10.5194/gmd-9-3461-2016.

Perovich, D. K., B. Light, H. Eicken, K. F. Jones, K. Runciman, and S. V. Nghiem, 2007: Increasing solar heating of the Arctic Ocean and adjacent seas, 1979-2005: Attribution and role in the ice-albedo feedback. Geophys. Res. Lett., 34, L19505, https://doi.org/10.1029/2007GL031480.
Qu, X., and G. Huang, 2019: Global monsoon changes under the Paris agreement temperature goals in CESM1(CAM5). Adv. Atmos. Sci., 36, 279-291, https://doi.org/10.1007/s00376-018-8138-y.

Rhodes, C. J., 2016: The 2015 Paris climate change conference: COP21. Sci. Prog., 99, 97-104, https://doi.org/10.3184/ $003685016 X 14528569315192$.

Riahi, K., and Coauthors, 2017: The shared socioeconomic pathways and their energy, land use, and greenhouse gas emissions implications: An overview. Global Environ. Change, 42, 153168, https://doi.org/10.1016/j.gloenvcha.2016.05.009.

Righi, M., and Coauthors, 2020: Earth System Model Evaluation Tool (ESMValTool) v2.0-Technical overview. Geosci. Model Dev., 13, 1179-1199, https://doi.org/10.5194/gmd-13-1179-2020.

Scheff, J., and D. M. Frierson, 2015: Terrestrial aridity and its response to greenhouse warming across CMIP5 climate models. J. Climate, 28, 5583-5600, https://doi.org/10.1175/JCLI-D-14-00480.1.

Schewe, J., and A. Levermann, 2017: Non-linear intensification of Sahel rainfall as a possible dynamic response to future warming. Earth Syst. Dyn., 8, 495-505, https://doi.org/10.5194/ esd-8-495-2017.

Schleussner, C. F., and Coauthors, 2016: Differential climate impacts for policy-relevant limits to global warming: The case of $1.5^{\circ} \mathrm{C}$ and $2^{\circ} \mathrm{C}$. Earth Syst. Dyn., 7, 327-351, https://doi.org/ 10.5194/esd-7-327-2016.

Schurer, A. P., M. E. Mann, E. Hawkins, S. F. Tett, and G. C. Hegerl, 2017: Importance of the pre-industrial baseline for likelihood of exceeding Paris goals. Nat. Climate Change, 7, 563-567, https://doi.org/10.1038/nclimate3345.

Screen, J. A., and I. Simmonds, 2010: The central role of diminishing sea ice in recent Arctic temperature amplification. Nature, 464, 1334-1337, https://doi.org/10.1038/nature09051.

- and D. Williamson, 2017: Ice-free Arctic at $1.5^{\circ} \mathrm{C}$ ? Nat. Climate Change, 7, 230-231, https://doi.org/10.1038/nclimate3248.

—, C. Deser, and I. Simmonds, 2012: Local and remote controls on observed Arctic warming. Geophys. Res. Lett., 39, L10709, https://doi.org/10.1029/2012GL051598.

Sellar, A. A., and Coauthors, 2019: UKESM1: Description and evaluation of the UK Earth System Model.J. Adv. Model. Earth Syst., 11, 4513-4558, https://doi.org/10.1029/2019MS001739.

Seneviratne, S. I., and Coauthors, 2021: Weather and climate extreme events in a changing climate. Climate Change 2021: The Physical Science Basis, P. Z. V. Masson-Delmotte et al., Eds., Cambridge University Press, https://www.ipcc.ch/report/sixthassessment-report-working-group-i/, in press.

Serreze, M. C., and R. G. Barry, 2011: Processes and impacts of Arctic amplification: A research synthesis. Global Planet. Change, 77, 85-96, https://doi.org/10.1016/j.gloplacha.2011.03.004.

— A. P. Barrett, J. C. Stroeve, D. N. Kindig, and M. M. Holland, 2009: The emergence of surface-based Arctic amplification. Cryosphere, 3, 11-19, https://doi.org/10.5194/tc-3-11-2009.

,-- , and,- 2012 : Recent changes in tropospheric water vapor over the Arctic as assessed from radiosondes and atmospheric reanalyses. J. Geophys. Res., 117, D10104, https:// doi.org/10.1029/2011JD017421.

Sigmond, M., J. C. Fyfe, and N. C. Swart, 2018: Ice-free Arctic projections under the Paris agreement. Nat. Climate Change, 8, 404-408, https://doi.org/10.1038/s41558-018-0124-y.

Smith, D., and Coauthors, 2018: Predicted chance that global warming will temporarily exceed $1.5^{\circ} \mathrm{C}$. Geophys. Res. Lett., 45, 11 895-11 903, https://doi.org/10.1029/2018GL079362.

Stuecker, M. F., and Coauthors, 2018: Polar amplification dominated by local forcing and feedbacks. Nat. Climate Change, $\mathbf{8}$, 1076-1081, https://doi.org/10.1038/s41558-018-0339-y. 
Swann, A. L., I. Y. Fung, S. Levis, G. B. Bonan, and S. C. Doney, 2010: Changes in Arctic vegetation amplify high-latitude warming through the greenhouse effect. Proc. Natl. Acad. Sci. USA, 107, 1295-1300, https://doi.org/10.1073/pnas.0913846107.

Tang, Q., and G. Leng, 2012: Damped summer warming accompanied with cloud cover increase over Eurasia from 1982 to 2009. Environ. Res. Lett., 7, 014004, https://doi.org/10.1088/1748-9326/7/1/014004.

Taylor, K., R. Stouffer, and G. Meehl, 2009: A summary of the CMIP5 experiment design. PCMDI Rep., 33 pp., https:// pcmdi.llnl.gov/mips/cmip5/docs/Taylor_CMIP5_design.pdf.

Tebaldi, C., and J. M. Arblaster, 2014: Pattern scaling: Its strengths and limitations, and an update on the latest model simulations. Climatic Change, 122, 459-471, https://doi.org/10.1007/s10584013-1032-9.

- and R. Knutti, 2018: Evaluating the accuracy of climate change pattern emulation for low warming targets. Environ. Res. Lett., 13, 055006, https://doi.org/10.1088/1748-9326/aabef2.
- and Coauthors, 2021: Climate model projections from the Scenario Model Intercomparison Project (ScenarioMIP) of CMIP6. Earth Syst. Dyn., 12, 253-293, https://doi.org/10.5194/ esd-12-253-2021.

Wainwright, C. M., E. Black, and R. P. Allan, 2021: Future changes in wet and dry season characteristics in CMIP5 and CMIP6 simulations. J. Hydrometeor., 22, 2339-2357, 10.1175/JHM-D21-0017.1.

Wodzicki, K., and A. Rapp, 2016: Long-term characterization of the Pacific ITCZ using TRMM, GPCP, and ERA-Interim. J. Geophys. Res. Atmos., 121, 3153-3170, https://doi.org/ 10.1002/2015JD024458.

Zampieri, M., F. D'Andrea, R. Vautard, P. Ciais, N. de NobletDucoudré, and P. Yiou, 2009: Hot European summers and the role of soil moisture in the propagation of Mediterranean drought. J. Climate, 22, 4747-4758, https://doi.org/10.1175/ 2009JCLI2568.1. 